\title{
Timing of the Critical Period for Plasticity of Ocular Dominance Columns in Macaque Striate Cortex
}

\author{
Jonathan C. Horton and Davina R. Hocking \\ Beckman Vision Center, University of California, San Francisco, San Francisco, California 94143-0730
}

\begin{abstract}
Visual deprivation induced by monocular eyelid suture, a laboratory model for congenital cataract, results in shrinkage of ocular dominance columns serving the closed eye. We performed monocular suture in macaques at ages 1, 3, 5, 7, and 12 weeks to define the critical period for plasticity of ocular dominance columns. After a minimum survival of 8 months, complete montages of $\left[{ }^{3} \mathrm{H}\right]$ proline-labeled columns were reconstructed from flat-mounts of striate cortex in both hemispheres. In any given monkey, visual deprivation induced the columns throughout striate cortex (V1) to retract the same distance from their original borders in layer IVc $\beta$. After deprivation, the widest columns remained in the foveal representation and along the V1/V2 border, where columns are widest in control animals. The narrowest deprived columns belonged to the ipsilateral eye, especially along the horizontal meridian and in the periphery, where columns are narrowest in control animals. At the earliest age that we tested ( 1 week), visual deprivation reduced the columns to fragments. These fragments always coincided with a cytochrome oxidase patch, or a short string of patches, in the
\end{abstract}

upper layers. More severe column shrinkage occurred in layer IVc $\beta$ (parvo) than layer IVc $\alpha$ (magno). The geniculate input to the patches in layer III (konio) appeared normal after deprivation, despite loss of CO activity. Surprisingly, the blind spot representation of the open eye was shrunken by monocular deprivation, although binocular competition is absent in this region. Our principal finding was that eyelid suture at age 1 week caused the most severe column shrinkage. With suture at later ages, the degree of column shrinkage showed a progressive decline. Deprivation commencing at age 12 weeks caused no column shrinkage. These results imply that primate visual cortex is most vulnerable to deprivation during the first weeks of life. Our experiments should provide further impetus for the treatment of children with congenital cataract at the earliest possible age.

Key Words: ocular dominance column; critical period; amblyopia; visual deprivation; cytochrome oxidase patch; flat-mount; striate cortex
The most severe form of amblyopia develops when a newborn child is deprived of vision in one eye by a dense unilateral cataract (Boothe et al., 1985). In a series of landmark experiments, Wiesel and Hubel $(1963,1965)$ raised kittens with the lids of one eye sutured to simulate congenital monocular cataract. Electrophysiological recordings from striate cortex (V1) revealed that few cells could be driven via the deprived eye. Later, the anatomical correlate of this shift in ocular dominance was shown in cats and monkeys by intraocular injection of $\left[{ }^{3} \mathrm{H}\right]$ proline (Hubel et al., 1977; Shatz and Stryker, 1978; Swindale et al., 1981). The ocular dominance columns serving the deprived eye appeared severely shrunken because of contraction of their geniculocortical terminal arbors. Wiesel and Hubel (see Wiesel, 1982) proposed that visual deprivation produces amblyopia by causing the deprived eye to become disconnected from the cortical circuits required for the normal processing of retinal input.

Received Dec. 19, 1996; revised Feb. 7, 1997; accepted Feb. 25, 1997.

This work was supported by grants from the National Eye Institute, That Man May See, and Research to Prevent Blindness. We thank the New England Regional Primate Research Center (especially Dr. Prabhat Sehgal) and the California Regional Primate Research Center (especially Dr. Celia Valverde, Jenny Short, and David Robb) for their help. The California Primate Center is supported by National Institutes of Health Base Grant RR00169. Robin Troyer assisted with these experiments. The first experiment (Monkey 0) was performed in collaboration with Dr. Michael P. Stryker. We thank him for his critical review of this manuscript. Dr. Torsten N. Wiesel, Dr. Simon LeVay, and Dr. Michael C. Crair also provided many useful comments.

Correspondence should be addressed to Dr. Jonathan C. Horton, Beckman Vision Center, 10 Kirkham Street, University of California, San Francisco, San Francisco, CA 94143-0730.

Copyright (C) 1997 Society for Neuroscience $\quad 0270-6474 / 97 / 173684-26 \$ 05.00 / 0$
Ocular dominance columns are vulnerable to shrinkage for only a short time after birth, called the "critical period" (Hubel and Wiesel, 1970). Once neonates develop beyond the critical period, the width of their ocular dominance columns becomes immutable. To define the beginning and the end of the critical period, LeVay et al. (1980) performed monocular suture in a series of $10 \mathrm{ma}$ caques at successively later ages, ranging from $2 \mathrm{~d}$ to adult. To their surprise, the age at eyelid suture seemed to make no difference for the first 6 weeks of life. The same degree of column shrinkage was found in all animals sutured during this interval. The critical period did not appear to wane until $\sim 10$ weeks, when eyelid closure caused only mild column shrinkage. The end of the critical period was not defined exactly, but eyelid suture at 7 months had no effect.

Results obtained from these animal experiments have altered the management of congenital cataract in children. Before 1980, the prognosis for monocular congenital cataract was considered dismal and successful visual rehabilitation was virtually unknown (Cordes, 1957; Costenbader and Albert, 1957; Ryan et al., 1965; Parkes and Hiles, 1967; Francois, 1979). After the discovery of the critical period for plasticity of ocular dominance columns, a few innovative clinicians showed that good vision could be obtained in children if cataract surgery were performed at an early age, followed by immediate optical correction and vigorous patching therapy (Enoch and Rabinowicz, 1976; Beller et al., 1981; PrattJohnson and Tillson, 1981). It has now become accepted practice that dense, monocular cataract should be removed before age 4 months (Vaegan and Taylor, 1979; Rogers et al., 1981; Birch and 


\begin{tabular}{|c|c|c|c|c|c|c|c|c|}
\hline & Monkey 1 & Monkey 2 & Monkey 3 & Monkey 4 & Monkey 5 & Monkey 6 & Monkey 7 & Monkey 8 \\
\hline Sex & male & male & male & male & female & male & male & male \\
\hline Length of gestation (d) & E167 & E166 & E167 & E164 & E167 & E164 & E165 & E165 \\
\hline Macaque species & fascicularis & fascicularis & mulatta & mulatta & mulatta & mulatta & mulatta & mulatta \\
\hline Age at suture & $7 \mathrm{~d}$ & $7 \mathrm{~d}$ & $7 \mathrm{~d}$ & $21 \mathrm{~d}$ & $35 \mathrm{~d}$ & $35 \mathrm{~d}$ & $49 \mathrm{~d}$ & $84 \mathrm{~d}$ \\
\hline Eye sutured & right & right & right & right & right & right & right & right \\
\hline Eye injected & right & right & left & left & left & left & left & left \\
\hline Eye enucleated & right & - & right & right & - & right & right & - \\
\hline $\begin{array}{l}\text { Survival time } \\
\text { after enucleation }\end{array}$ & $10 \mathrm{~d}$ & - & $58 \mathrm{~d}$ & $24 \mathrm{~d}$ & - & $42 \mathrm{~d}$ & $20 \mathrm{~d}$ & - \\
\hline Age at perfusion & 11 months & 14 months & 11 months & 8 months & 26 months & 15 months & 8 months & 15 months \\
\hline Weight at Perfusion & $1.47 \mathrm{~kg}$ & $1.87 \mathrm{~kg}$ & $1.53 \mathrm{~kg}$ & $1.38 \mathrm{~kg}$ & $3.14 \mathrm{~kg}$ & $1.93 \mathrm{~kg}$ & $1.64 \mathrm{~kg}$ & $2.21 \mathrm{~kg}$ \\
\hline
\end{tabular}

Stager, 1988; Drummond et al., 1989; Cheng et al., 1991; Wright et al., 1992; Birch et al., 1993). However, there is still no consensus about the urgency of cataract surgery within this time frame (Birch and Stager, 1996). Hoyt removed a dense, monocular cataract from a baby $7 \mathrm{hr}$ after birth, and the child attained an acuity of 20/20 (Beller et al., 1981). Is such early action warranted, or does surgery anytime during a "grace period" of a few weeks or months after birth produce comparable results?

To furnish anatomical data pertinent to this issue, we repeated the experiments of LeVay et al. (1980) by performing monocular eyelid suture in a series of baby macaques at successively later ages. After the monkeys were at least 8 months old, flat-mounts of striate cortex were prepared from each animal to measure the amount of column shrinkage. In most animals, we reconstructed the entire pattern of ocular dominance columns to avoid sampling bias that might arise from examining only a small area. Preparing flat-mounts also allowed us to determine whether columns vary in their susceptibility to shrinkage according to their location within

Table 2. Measurements of striate cortex

\begin{tabular}{|c|c|c|c|c|c|c|c|c|c|c|c|c|c|c|c|c|}
\hline Animal number & \multicolumn{2}{|c|}{ Monkey 1} & \multicolumn{2}{|c|}{ Monkey 2} & \multicolumn{2}{|c|}{ Monkey 3} & \multicolumn{2}{|c|}{ Monkey 4} & \multicolumn{2}{|c|}{ Monkey 5} & \multicolumn{2}{|c|}{ Monkey 6} & \multicolumn{2}{|c|}{ Monkey 7} & \multicolumn{2}{|c|}{ Monkey 8} \\
\hline Sutured & \multicolumn{2}{|c|}{1 week } & \multicolumn{2}{|c|}{1 week } & \multicolumn{2}{|c|}{1 week } & \multicolumn{2}{|c|}{3 weeks } & \multicolumn{2}{|c|}{5 weeks } & \multicolumn{2}{|c|}{5 weeks } & \multicolumn{2}{|c|}{7 weeks } & \multicolumn{2}{|c|}{12 weeks } \\
\hline Hemisphere & left & right & left & right & left & right & left & right & left & right & left & right & left & right & left & right \\
\hline $\mathrm{V} 1$ area $\left(\mathrm{mm}^{2}\right)$ & $461^{a}$ & $441^{a}$ & $404^{a}$ & $452^{a}$ & 1362 & 1414 & 1241 & 1226 & 895 & 1014 & 1075 & 1034 & 1575 & 1612 & 1379 & 1331 \\
\hline $\begin{array}{l}\text { Unreconstructable } \\
\text { area }\left(\mathrm{mm}^{2}\right)\end{array}$ & 49 & 33 & 44 & 44 & 159 & 144 & 28 & 47 & 37 & 22 & 14 & 11 & 13 & 52 & 78 & 117 \\
\hline $\begin{array}{l}\text { Total \# column } \\
\text { pairs intersect- } \\
\text { ing V1 Border }\end{array}$ & - & - & - & - & - & - & 118 & 124 & 127 & 123 & 145 & 145 & 122 & 115 & 136 & 136 \\
\hline $\begin{array}{l}\text { Optic disc area } \\
\left(\mathrm{mm}^{2}\right)\end{array}$ & - & - & - & - & $12^{b}$ & 4 & 12 & 7 & 10 & 7 & 11 & 8 & 14 & 10 & 12 & 11 \\
\hline $\begin{array}{l}\text { Monocular crescent } \\
\text { area }\left(\mathrm{mm}^{2}\right)\end{array}$ & - & - & - & - & 78 & $84^{b}$ & 48 & 64 & 49 & 67 & 63 & 65 & 83 & 99 & 55 & 48 \\
\hline Operculum & & & & & & & & & & & & & & & & \\
\hline $\begin{array}{l}\text { Left (nondeprived) } \\
\text { eye column area } \\
\left(\mathrm{mm}^{2}\right)\end{array}$ & $\begin{array}{l}346 \\
(83.8 \%)\end{array}$ & $\begin{array}{l}344 \\
(84.1 \%)^{c} \\
\end{array}$ & $\begin{array}{l}331 \\
c(92.2 \%)\end{array}$ & $\begin{array}{l}360 \\
(88.0 \%) \\
\end{array}$ & $\begin{array}{l}525 \\
(88.0 \%)\end{array}$ & $\begin{array}{l}637 \\
(91.7 \%) \\
\end{array}$ & $\begin{array}{l}387 \\
(63.3 \%)\end{array}$ & $\begin{array}{l}432 \\
(72.5 \%) \\
\end{array}$ & $\begin{array}{l}311 \\
(64.7 \%)\end{array}$ & $\begin{array}{l}318 \\
(63.7 \%) \\
\end{array}$ & $\begin{array}{l}302 \\
(56.8 \%)\end{array}$ & $\begin{array}{l}334 \\
(62.8 \%) \\
\end{array}$ & $\begin{array}{l}425 \\
(53.1 \%)\end{array}$ & $\begin{array}{l}431 \\
(58.2 \%) \\
\end{array}$ & $\begin{array}{l}331 \\
(49.1 \%)\end{array}$ & $\begin{array}{l}335 \\
(51.9 \%) \\
\end{array}$ \\
\hline $\begin{array}{l}\text { Right (deprived) } \\
\text { eye column area }\end{array}$ & 67 & 65 & 28 & 49 & 71 & 58 & 224 & 164 & 170 & 181 & 230 & 198 & 376 & 309 & 343 & 311 \\
\hline$\left(\mathrm{mm}^{2}\right)$ & $(16.2 \%)$ & $(15.9 \%)$ & $(7.8 \%)$ & $(12.0 \%)$ & $(12.0 \%)$ & $(8.3 \%)$ & $(36.7 \%)$ & $(27.5 \%)$ & $(35.3 \%)$ & $(36.3 \%)$ & $(43.2 \%)$ & $(37.2 \%)$ & $(46.9 \%)$ & $(41.8 \%)$ & $(50.9 \%)$ & $(48.1 \%)$ \\
\hline Shrinkage $^{d}$ & $\underline{36 \%}$ & $32 \%$ & $\underline{44 \%}$ & $36 \%$ & $\underline{40 \%}$ & $40 \%$ & $\underline{15 \%}$ & $20 \%$ & $\underline{17 \%}$ & $12 \%$ & $9 \%$ & $11 \%$ & $5 \%$ & $6 \%$ & $1 \%$ & $0 \%$ \\
\hline Periphery & & & & & & & & & & & & & & & & \\
\hline$\overline{\text { Left eye column }}$ & & & & & 487 & 477 & 380 & 419 & 177 & 296 & 250 & 320 & 346 & 475 & 260 & 294 \\
\hline area $\left(\mathrm{mm}^{2}\right)$ & - & - & - & - & $(94.4 \%)$ & $(98.1 \%)$ & $(70.1 \%)$ & $(82.0 \%)$ & $(55.7 \%)$ & $(70.8 \%)$ & $(54.7 \%)$ & $(76.6 \%)$ & $(52.0 \%)$ & $(66.9 \%)$ & $(46.5 \%)$ & $(57.8 \%)$ \\
\hline Right eye column & & & & & 29 & 9 & 162 & 92 & 141 & 122 & 207 & 98 & 320 & 235 & 299 & 215 \\
\hline area $\left(\mathrm{mm}^{2}\right)$ & - & - & - & - & $(5.6 \%)$ & $(1.9 \%)$ & $(29.9 \%)$ & $(18.0 \%)$ & $(44.3 \%)$ & $(29.2 \%)$ & $(45.3 \%)$ & $(23.4 \%)$ & $(48.0 \%)$ & $(33.1 \%)$ & $(53.5 \%)$ & $(42.2 \%)$ \\
\hline Shrinkage $^{d}$ & - & - & - & - & $57 \%$ & $35 \%$ & $33 \%$ & $19 \%$ & $\underline{19 \%}$ & $8 \%$ & $18 \%$ & $14 \%$ & $15 \%$ & $4 \%$ & $10 \%$ & $-5 \%$ \\
\hline
\end{tabular}

${ }^{a}$ Data reflect area of the operculum only.

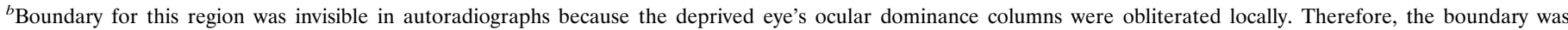
determined by reference to the appearance of $\mathrm{CO}$ patches in the upper layers.

${ }^{c}$ Underlined values denote contralateral eye.

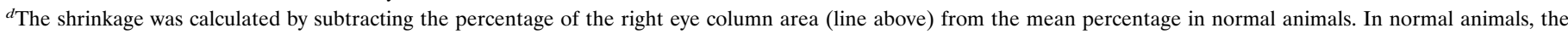

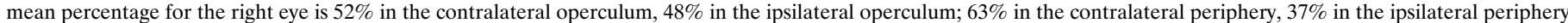
(Horton and Hocking, 1996c). 

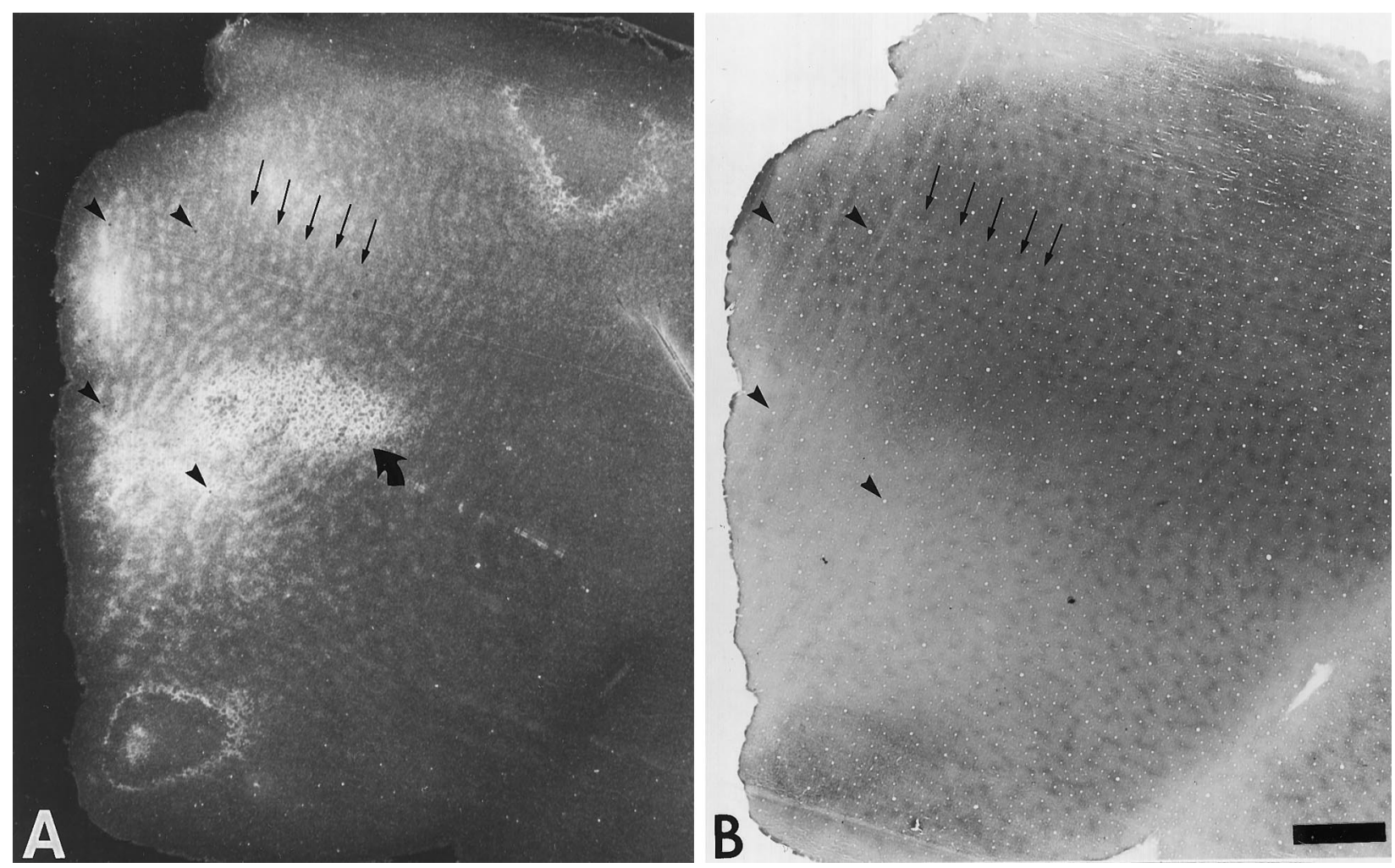

Figure 1. Monkey 0 (1 week suture). A, Autoradiograph of a single section passing through layer III in the medial half of the right operculum. The radioactive tracer appears bright in dark-field illumination. The section just grazed the honeycomb in layer IVa at its deepest point (curved arrow). Parallel rows of patches were labeled by saturating the lateral geniculate body with a huge injection of $\left[{ }^{3} \mathrm{H}\right]$ proline. The arrows indicate five rows of patches serving the normal left eye. Blood vessels used for section alignment are marked with arrowheads. $B$, Adjacent section showing the array of CO patches. The staining was poor, but one can detect alternating light and dark rows. The arrows mark five dark rows (left eye) that match the arrows in $A$. Comparison of $A$ and $B$ indicated that every row of $\mathrm{CO}$ patches was well labeled by $\left[{ }^{3} \mathrm{H}\right]$ proline; deprivation of the right eye caused no obvious attenuation of the koniocellular projection to its rows of $\mathrm{CO}$ patches. Scale bar, $2 \mathrm{~mm}$.

the overall mosaic (e.g., we measured shrinkage of foveal columns vs peripheral columns, ipsilateral columns vs contralateral columns, etc.). We also compared how the three major projections from the lateral geniculate body (parvo $\rightarrow$ layer IVc $\beta$; magno $\rightarrow$ layer IVc $\alpha$; konio $\rightarrow$ layers II and III) are affected by visual deprivation. Finally, we examined the relationship between the cytochrome oxidase (CO) patches ("puffs" or "blobs") and the shrunken islands of ocular dominance columns that survive in layer IVc after early monocular suture. The main finding emerging from this study is that the shrinkage of ocular dominance columns is greatest when visual deprivation begins right after birth, modifying the original conclusion reached by LeVay et al. (1980).

\section{MATERIALS AND METHODS}

Experimental animals and surgical procedures. The first experiment was performed on a single male Macaca fascicularis (Monkey 0) born at the New England Regional Primate Center. The right eyelids were sutured under general anesthesia with ketamine $\mathrm{HCl}(10 \mathrm{mg} / \mathrm{kg}$, i.m. $)$ at age 1 week. At age 11 months, the animal was transferred to the University of California, San Francisco (UCSF) for injection of $\left[{ }^{3} \mathrm{H}\right]$ proline into the lateral geniculate body, following a protocol approved by the UCSF Committee on Animal Research. Our procedures for making tracer injections and for preparing histological sections have been described elsewhere (Horton and Stryker, 1993a). In brief, $0.5 \mathrm{mCi}$ of $\left[{ }^{3} \mathrm{H}\right]$ proline in $2.5 \mu \mathrm{l}$ was deposited by pressure injection at the border between laminae 3 and 4 of the right lateral geniculate body. After a survival time of $2 \mathrm{~d}$, the monkey was given a lethal intravenous dose of thiopental and perfused with fixative. The right occipital lobe was sectioned parallel to the opercular surface (without unfolding and flat-mounting), and alternate sections were prepared for $\mathrm{CO}$ and autoradiography.

The remaining experiments were performed in eight unrelated macaques (Monkeys $1-8$ ) bred by timed matings at the California Regional Primate Research Center (Davis, CA). For the 1994 season, when most of these animals were born, mean gestation in the colony was $165 \mathrm{~d}$ (SD, $\pm 8.9 \mathrm{~d}, n=61$ ). This wide variability represented a potential confounding factor, because two animals sutured the same time after birth might easily differ by several weeks in their gestational age and, therefore, in their susceptibility to visual deprivation. To minimize this problem, the veterinary staff allowed us to select babies from the colony born naturally within $2 \mathrm{~d}$ of full gestation [embryonic day 163 (E163) to E167].

All experimental procedures were approved by the Committees on Animal Research at the University of California, Davis and UCSF. To induce amblyopia, the lids of the right eye were sutured at exactly $1,3,5$, 7 , or 12 weeks after birth (Table 1). Tarsorrhaphy was performed under anesthesia with ketamine $\mathrm{HCl}(10 \mathrm{mg} / \mathrm{kg}$, i.m. $)$. After the eyelids were infiltrated with $0.5 \%$ lidocaine plus epinephrine $(1: 200,000)$, they were trimmed to expose the tarsal plates and fused with 6-0 Vicryl interrupted horizontal mattress sutures. The babies were examined daily for a week to verify that the eyelids were sealed. The eyelids healed completely in every animal within 1 week.

When the animals were at least 7 months old, they were transferred to UCSF to label their ocular dominance columns with $\left[{ }^{3} \mathrm{H}\right]$ proline. The tracer was prepared by reconstituting $2 \mathrm{mCi}$ of $\mathrm{L}-\left[2,3,4,5-{ }^{3} \mathrm{H}\right]$ proline (specific activity 102-106 Ci/mmol; Amersham, Arlington Heights, I)L in $20 \mu \mathrm{l}$ of sterile balanced salt solution. It was injected into the mid-vitreous of either the amblyopic right eye or the normal left eye (Table 1) under anesthesia with ketamine $\mathrm{HCl}(10 \mathrm{mg} / \mathrm{kg}$, i.m.) and topical proparacaine $\mathrm{HCl}$. Immediately after, the fundus was examined with an indirect ophthalmoscope to verify that no injury had occurred. For tracer injection into the amblyopic eye (Monkeys 1 and 2), the eyelids were opened 

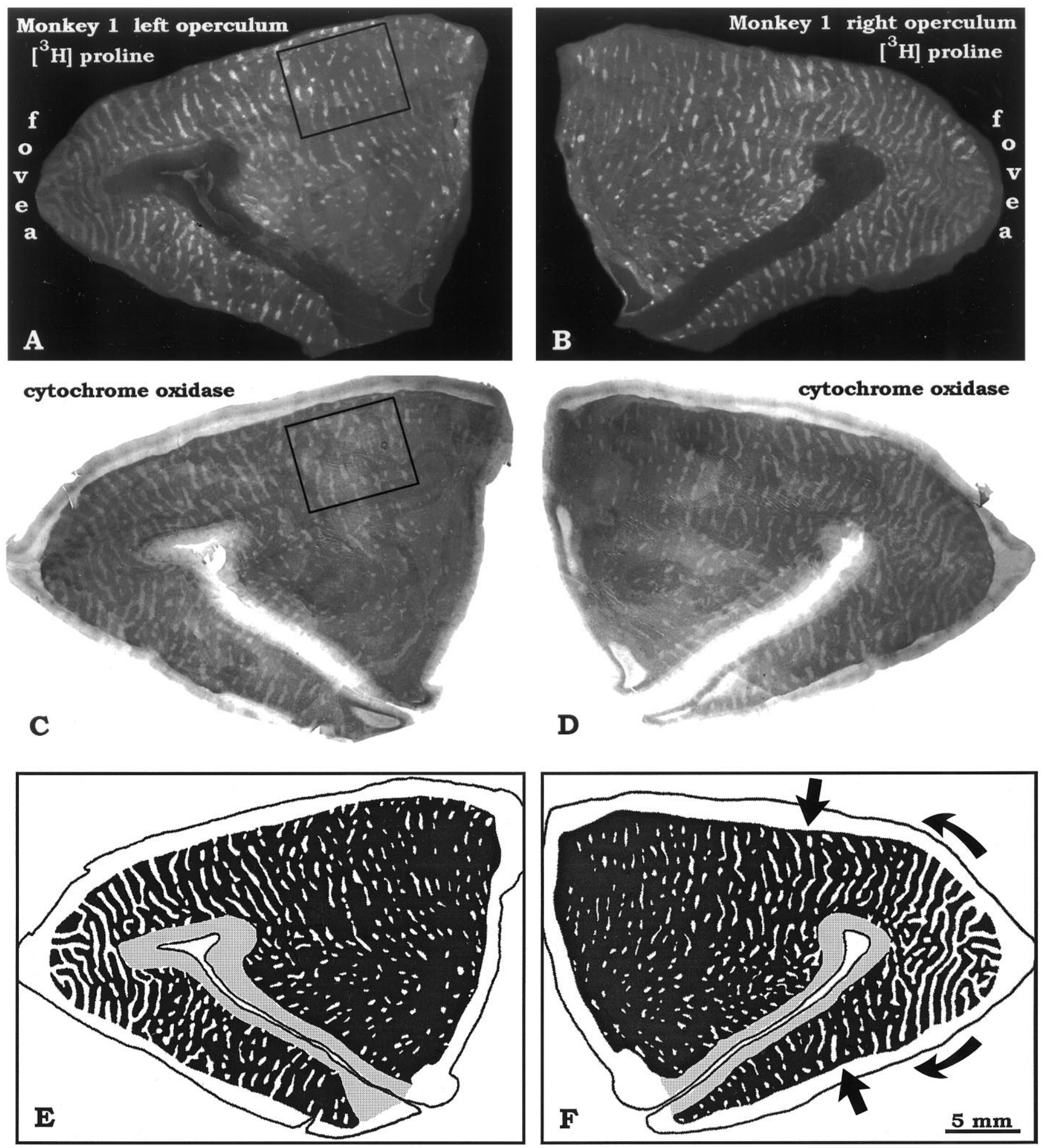

Figure 2. Monkey 1 (1 week suture). A, B, Montages of autoradiographs showing severe shrinkage of ocular dominance columns in layer IVc $\beta$. The deprived right eye was injected with $\left[{ }^{3} \mathrm{H}\right]$ proline at age 11 months and enucleated 1 week later. Tissues were processed after an additional $10 \mathrm{~d}$ survival period. The region within the box is shown in Figure $3 A$ at higher power. $C, D$, Montages of adjacent $C O$ sections, showing a labeling pattern in layer $\mathrm{IVc} \beta$ matching the autoradiographs above. The boxed region in $C$ is shown in Figure $3 B$. E, F, Drawing of the autoradiographs in $A$ and $B$ showing how the deprived columns become gradually more fragmented moving from the fovea to the periphery (curved arrows) and from the vertical meridian to the horizontal meridian (straight arrows). The latter effect is less striking. See Figure 7 for the retinotopic coordinates of V1. Areas shaded with gray could not be reconstructed. 

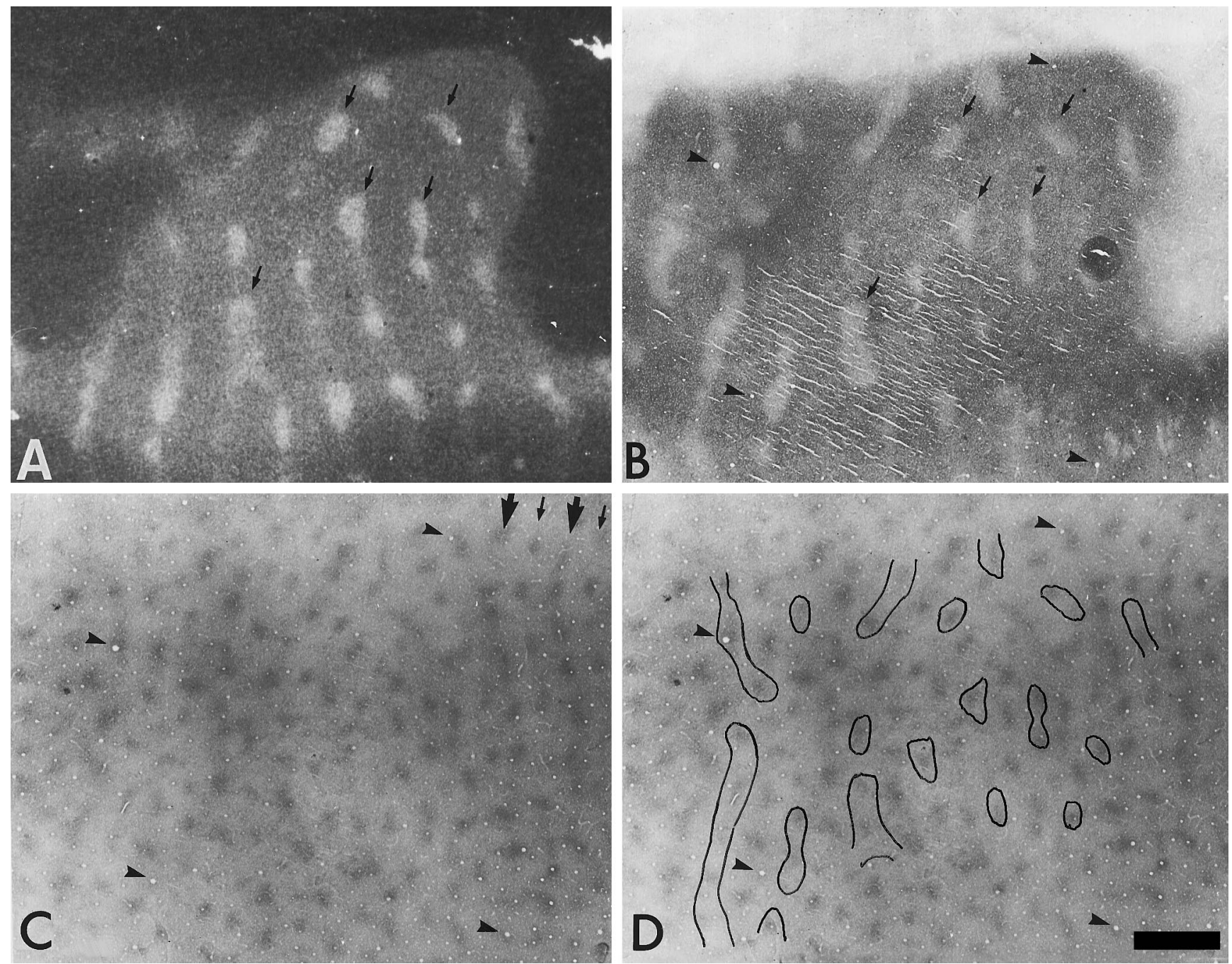

Figure 3. Monkey 1 ( 1 week suture). $A$, Autoradiograph from the box in Figure $2 A$, showing shrunken column fragments (arrows) in layer IVc $\beta$. $B$, Adjacent CO section, from the box in Figure $2 C$, showing pale, shrunken columns (arrows) in layer IVc $\beta$ after enucleation of the deprived right eye. The match between the columns labeled by autoradiography and $\mathrm{CO}$ is excellent. $C$, Array of $\mathrm{CO}$ patches in layer III from the same region of cortex shown in the preceding panel. The patches are organized into dark (large arrows) and light (small arrows) rows. $D$, Tracing of the column fragments in $B$ onto the $\mathrm{CO}$ patches in $C$. The column remnants coincide with the $\mathrm{CO}$ patches, always encircling individual patches or clusters of patches. Blood vessels used to align sections in $B-D$ are marked by arrowheads. Scale bar, $1 \mathrm{~mm}$ (all panels to scale).

briefly and then resutured. Survival times after eye injection were $7-9 \mathrm{~d}$, except for Monkey 1 , whose survival time was $17 \mathrm{~d}$.

In five monkeys, the ocular dominance columns were double-labeled by enucleating the amblyopic right eye and staining the cortex for $\mathrm{CO}$ (Table 1). Enucleation was performed using sterile technique under anesthesia with ketamine $\mathrm{HCl}(20 \mathrm{mg} / \mathrm{kg}$, i.m.) and a retrobulbar injection of $2 \mathrm{ml}$ of $1 \%$ lidocaine plus epinephrine $(1: 100,000)$. After surgery, buprenorphine $\mathrm{HCl}(0.02 \mathrm{mg} / \mathrm{kg}$, i.m.) was administered every $8 \mathrm{hr}$ for $2 \mathrm{~d}$ to ensure analgesia. Survival times ranged between 10 and $58 \mathrm{~d}$ (Table 1). Enucleation was done no earlier than age 7 months (well after the critical period) so that it would have no confounding effect on the width of the ocular dominance columns (LeVay et al., 1980).

We enucleated one eye to have CO available as a "back-up" label in case the autoradiography failed. In the end, the autoradiography succeeded in each animal, so it was not necessary to reconstruct the ocular dominance columns from the $\mathrm{CO}$ sections. However, for the sake of comparison we reconstructed the ocular dominance columns using both methods in Monkey 1.

Histological procedures. Before perfusion, the eye injected with $\left[{ }^{3} \mathrm{H}\right]$ proline was examined again under ketamine anesthesia $(20 \mathrm{mg} / \mathrm{kg}$, i.m.) with an indirect ophthalmoscope to verify that no injury had resulted from the tracer injection. In every case, the injected eye appeared undamaged (in Monkey 1, this procedure was done before enucleation of the right eye, rather than before perfusion). After receiving a lethal injection of sodium pentobarbital into the peritoneal cavity, each monkey was perfused through the left ventricle with 11 of normal saline followed by 11 of $2 \%$ paraformaldehyde in $0.1 \mathrm{M}$ phosphate buffer. Striate cortex from each occipital lobe was unfolded, flattened, and sectioned at $30 \mu \mathrm{m}$. Alternate sections were reacted for CO (Wong-Riley, 1979) or coated with emulsion for autoradiography (Wiesel et al., 1974). Our methods for preparing flat-mounts and processing sections have been described in detail previously (Horton and Hocking, 1996b,c).

Data analysis. The autoradiographs were photographed in dark-field illumination using Technical Pan film (Eastman Kodak, Rochester, NY) and developed with Technidol developer (Eastman Kodak). CO sections were photographed in bright-field using Plus-X Pan film (Eastman Kodak) and developed with Microdol-X (Eastman Kodak). Negatives were scanned into the computer and montages were prepared using Photoshop 3.0 (Adobe Systems) (Horton and Hocking, 1996b,c). To prepare black and white drawings, we created a transparent layer overlying the completed montage, traced the borders of the dark columns at high magnification on the monitor using the "pencil" function at a 1 pixel setting, and then flood-filled them with black. For quantification of column areas, the drawings were analyzed with Mocha (Jandel Scientific, 
San Rafael, CA). This program uses a thresholding function to assign pixels to black (level of gray $=1$ ) or white (level of gray $=256$ ). Pixels were converted to $\mathrm{mm}^{2}$ by calibration with the scale bar. Intermediate levels of gray were used to measure the unreconstructable areas, blind spots, and monocular crescents. To facilitate comparison between experiments, all montages in this paper were reproduced at identical scale.

\section{RESULTS}

\section{Monkey 0 (deprived at age 1 week)}

The goal of this experiment was to fill the thalamic projection to the $\mathrm{CO}$ patches in the upper layers of striate cortex by depositing a massive quantity $(0.5 \mathrm{mCi})$ of $\left[{ }^{3} \mathrm{H}\right]$ proline into the middle of the right lateral geniculate body. After injection, layer IVc was densely labeled throughout the entire flat, exposed lateral convexity of the right occipital lobe. This region, called the operculum, represents the central $0^{\circ}-8^{\circ}$ of the contralateral visual hemifield (see Fig. 7 for retinotopic coordinates of V1). The upper layers were labeled only in the medial half of the operculum, from $\sim 2.5^{\circ}-8^{\circ}$ (Fig. $1 A$ ). Autoradiographs revealed rows of patches in layer III, merging together like pearls on a string. An adjacent $\mathrm{CO}$ section showed alternating rows of light and dark patches (Fig. $1 B)$, as reported previously after visual deprivation at age 1 week (Horton and Stryker, 1993a). The adjacent sections matched: every row of $\mathrm{CO}$ patches coincided with a row of proline label. Despite shrinkage of the right eye's ocular dominance columns in layer IVc (which was not well seen, because the geniculocortical afferents serving both eyes were flooded with $\left[{ }^{3} \mathrm{H}\right]$ proline), the projection to the upper layers seemed normal. In fact, without referring to the adjacent $\mathrm{CO}$ section, we could not tell which rows of proline patches belonged to the deprived eye. This result implied that the koniocellular projection to the upper layers was less susceptible to visual deprivation than the parvocellular projection to layer $\operatorname{IVc} \beta$.

\section{Monkey 1 (deprived at age 1 week)}

This animal received an injection of $\left[{ }^{3} \mathrm{H}\right]$ proline into the deprived right eye. Autoradiographs showed severe shrinkage of the ocular dominance columns on the opercula (Fig. $2 A, B$ ). Only $16 \%$ of layer IVc $\beta$ in each hemisphere was occupied by geniculate afferents serving the amblyopic right eye (Table 2). The pattern of column shrinkage showed two gradients: the columns became smaller and more fragmented moving (1) from the fovea to the periphery and (2) from the vertical meridian to the horizontal meridian. Together, these two gradients reduced the deprived eye's columns to scattered islands along the horizontal meridian at $8^{\circ}$. By contrast, the deprived eye's columns remained relatively intact within the foveal representation (Fig. $2 E, F$ ).

In this monkey, we double-labeled the ocular dominance columns with $\mathrm{CO}$ by enucleating the amblyopic right eye 1 week after injecting it with $\left[{ }^{3} \mathrm{H}\right]$ proline. After waiting an additional $10 \mathrm{~d}$, to allow cortical CO levels to drop after enucleation, we prepared alternate sections for autoradiography and $\mathrm{CO}$ (compare Fig. $2 A, B$ with $2 C, D$ ). In Figure $3, A$ and $B$, a small region of layer $\mathrm{IVc} \beta$ from an autoradiograph and an adjacent $\mathrm{CO}$ section is shown at higher power. The two labels appeared nearly identical, but small differences were evident on close scrutiny. We attributed these subtle discrepancies to the fact that the sections were adjacent, not the same, and therefore passed through layer IVc $\beta$ at slightly different depths. In addition, the columns were labeled more intensely by $\left[{ }^{3} \mathrm{H}\right]$ proline than $\mathrm{CO}$ in this animal, causing the boundaries of the proline columns to appear slightly expanded. The match between the CO columns and the proline columns confirmed a previous study showing that $\mathrm{CO}$ accurately labels the ocular dominance columns in deprived animals (Horton and Stryker, 1993a).

In Monkey 1, CO staining showed alternating rows of light and dark patches in the upper layers. The shrunken fragments of ocular dominance columns in layer IVc $\beta$ (Fig. 3B) were traced onto the array of $\mathrm{CO}$ patches (Fig. $3 C$ ) to test their relationship (Fig. 3D). The remnants of ocular dominance columns were always centered on $\mathrm{CO}$ patches. For example, where the ocular dominance columns were reduced to small islands, they encircled a single $\mathrm{CO}$ patch. Where longer column fragments survived, they encompassed a short string of $\mathrm{CO}$ patches. In these cases, the boundary of the shrunken column never ended on a $\mathrm{CO}$ patch but, instead, passed between two adjacent patches. These findings were verified by examining three regions at high power from each operculum, containing a total of 78 column fragments in layer $\operatorname{IVc} \beta$.

\section{Monkey 2 (deprived at age 1 week)}

The opercula of this animal showed severe shrinkage of the deprived right eye's columns in layer IVc $\beta$ (Fig. 4A,B,E,F). The effect was even more striking than in Monkey 1 (compare Figs. $2 E, F$ and $4 E, F)$. This difference illustrates that two animals deprived in an identical manner can vary in their degree of column shrinkage. In Monkey 2, unlike Monkey 1, the deprivation effect was asymmetric (compare Fig. $4 A, B$ ). The right eye's columns occupied $12 \%$ of the ipsilateral operculum, but only $8 \%$ of the contralateral operculum (Table 2).

It is difficult to compare $\left[{ }^{3} \mathrm{H}\right]$ proline columns in different sublayers of IVc, because they are more crisp and intense in layer IVc $\beta$ than in layer IVc $\alpha$ (see Fig. 30 in Horton, 1984). Nonetheless, we observed an obvious difference in the shrinkage of layers IVc $\alpha$ and IVc $\beta$ (compare Fig. $4 A, C$ ). Rather than breaking into fragments, the columns in layer IVc $\alpha$ appeared relatively intact, preserving their original stripe-like configuration. In all animals sutured at age 5 weeks or younger, there was less column shrinkage in layer IVc $\alpha$ than in layer IVc $\beta$. This finding implies that the magnocellular projection (layer IVc $\alpha$ ) is less vulnerable than the parvocellular projection (layer $\mathrm{IVc} \beta$ ) to the effects of visual deprivation.

In layer IVc, the $\mathrm{CO}$ activity was homogeneous (Horton and Stryker, 1993a). In layers II and III, there were alternating dark and pale rows of $\mathrm{CO}$ patches (Fig. $4 D$ ). We examined the relationship between the shrunken ocular dominance columns in layer IVc $\beta$ and the CO patches in layer III, seeking to corroborate our findings in Monkey 1 . Figure $5 A$ shows an autoradiograph from the right operculum of Monkey 2. Approximately 10 shrunken islands were labeled in layer IVc $\beta$. The perimeter of each column fragment encircled a single $\mathrm{CO}$ patch, or a cluster of patches, in the upper layers (Fig. $5 B, C$ ). This finding was confirmed by testing three regions from each operculum containing a total of 62 column fragments.

In Monkey 2, the shrinkage of ocular dominance columns was so severe that many $\mathrm{CO}$ patches in deprived rows came to be situated over regions of layer IVc $\beta$ taken over by the normal eye. These patches were not spared the loss of CO activity suffered by fellow patches remaining in territory held by the deprived eye: $\mathrm{CO}$ activity was reduced in all patches located within a deprived row (Figs. $4 D, 5 B$ ). This finding suggests that, although layer IVc $\beta$ was taken over by the open eye, functional connections serving the open eye were not established to the deprived eye's patches, leaving them with reduced metabolic activity.

In Monkeys 1 and 2, the ocular dominance columns of the 

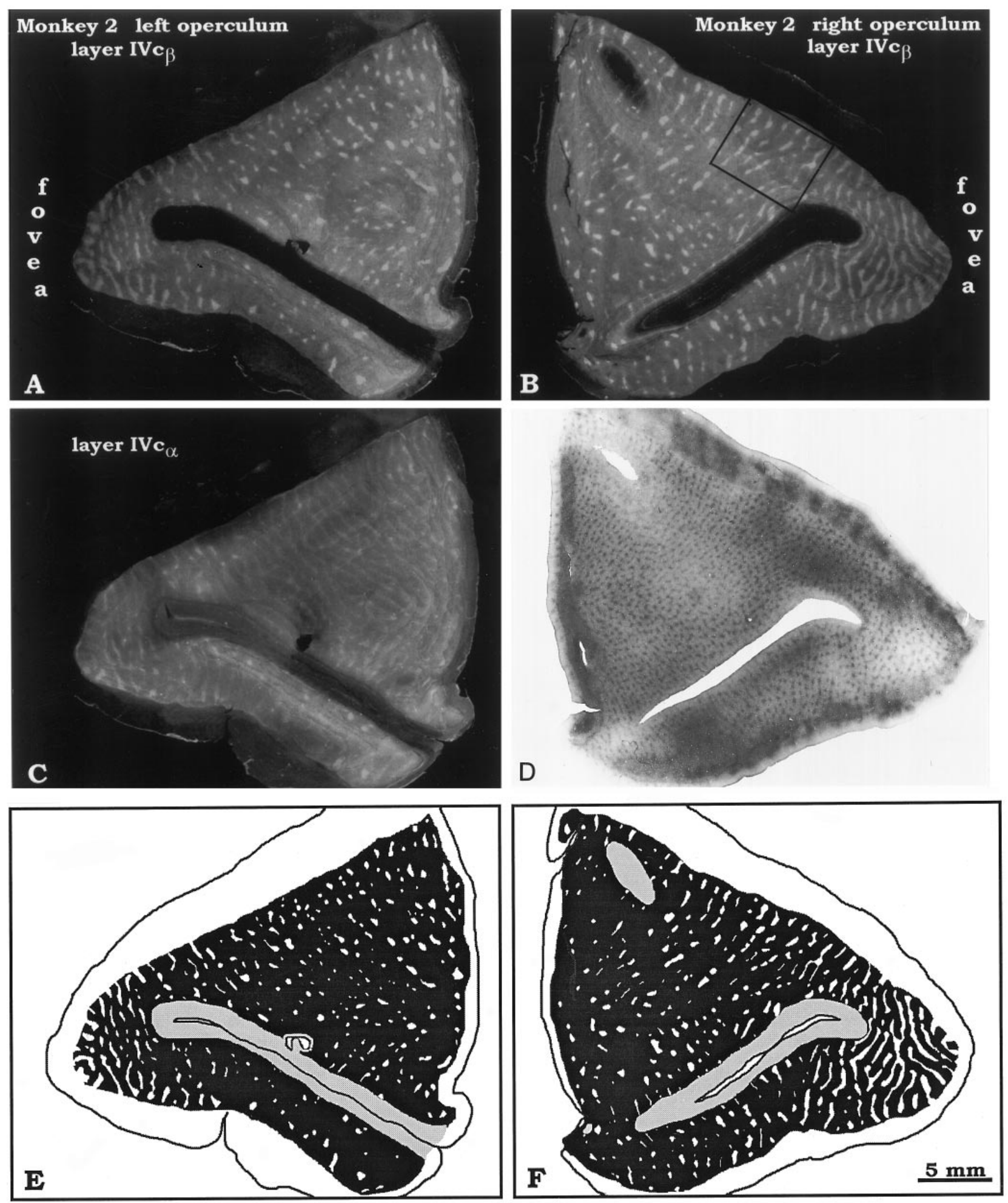

Figure 4. Monkey 2 (1 week suture). $A, B$, Montages of autoradiographs showing severe shrinkage of the right eye's columns labeled by [ $\left.{ }^{3} \mathrm{H}\right]$ proline. The columns were slightly more shrunken in the cortex contralateral (left V1) to the deprived eye, as one can appreciate by comparing the foveal regions in both hemispheres. The area within the box in $B$ appears in Figure 5. $C$, Montage of layer IVc $\alpha$ (magno) in the left operculum, showing less severe fragmentation of the ocular dominance columns, compared with the columns in layer IVc $\beta$ (parvo) in the panel above. $D$, CO-stained section showing rows of patches in the upper layers of the right operculum. Despite dramatic column shrinkage in layer IVc $\beta(B)$, CO staining in the deprived eye's rows of patches was only mildly reduced. $E, F$, Drawing of the montages in $A$ and $B$. 

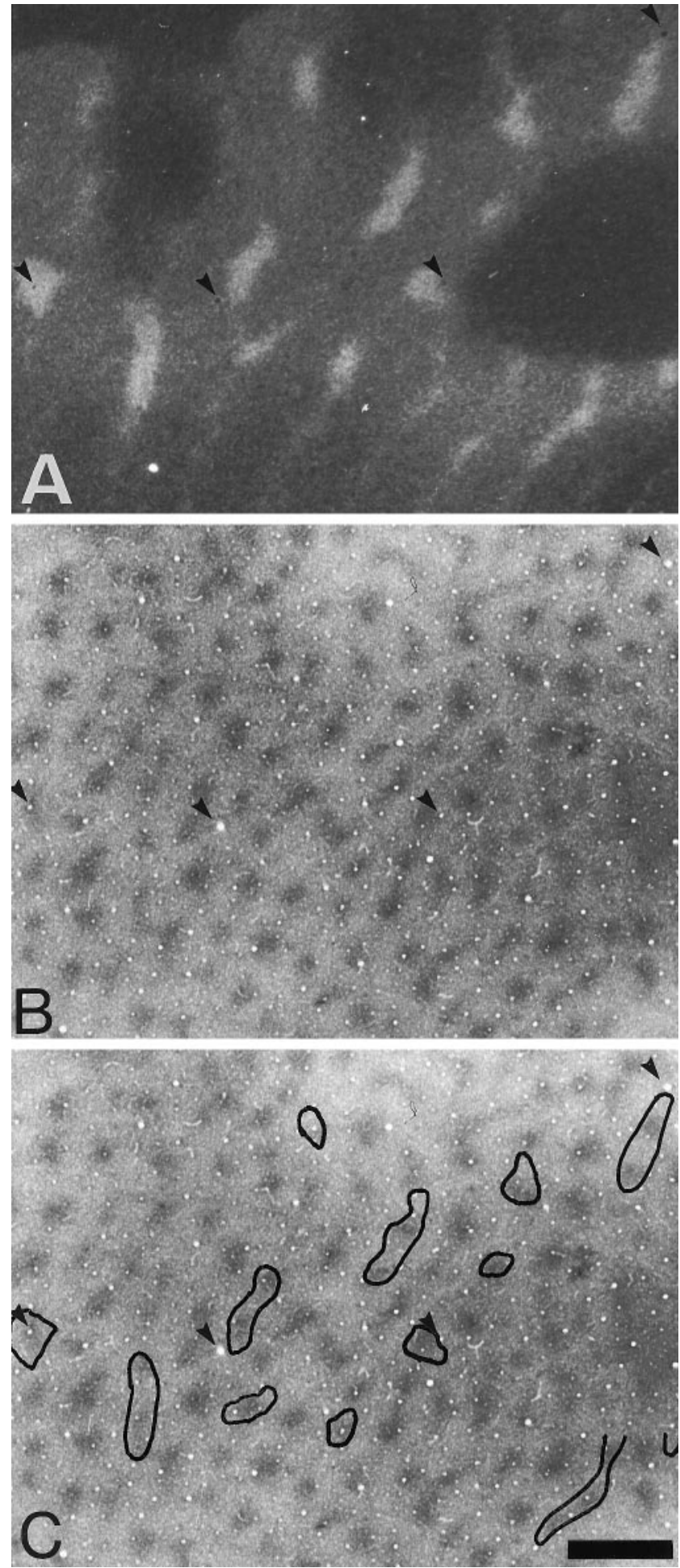

Figure 5. Monkey 2 (1 week suture). $A$, Single autoradiograph from the region enclosed by the box in Figure $4 B$, showing fragments of deprived right eye columns. $B$, CO section from the corresponding area in Figure $4 D$, showing the patches in the upper layers. $C$, Tracing of the column fragments in $A$ onto the $\mathrm{CO}$ patches in $B$, demonstrating that column remnants in layer IVc $\beta$ always encircle a $\mathrm{CO}$ patch or a short string of $\mathrm{CO}$ patches. Note that the $\mathrm{CO}$ patches circled in this figure are no more pale than other $\mathrm{CO}$ patches in deprived rows. Blood vessels used for section alignment are marked by arrowheads. Scale bar, $1 \mathrm{~mm}$ for all three panels.
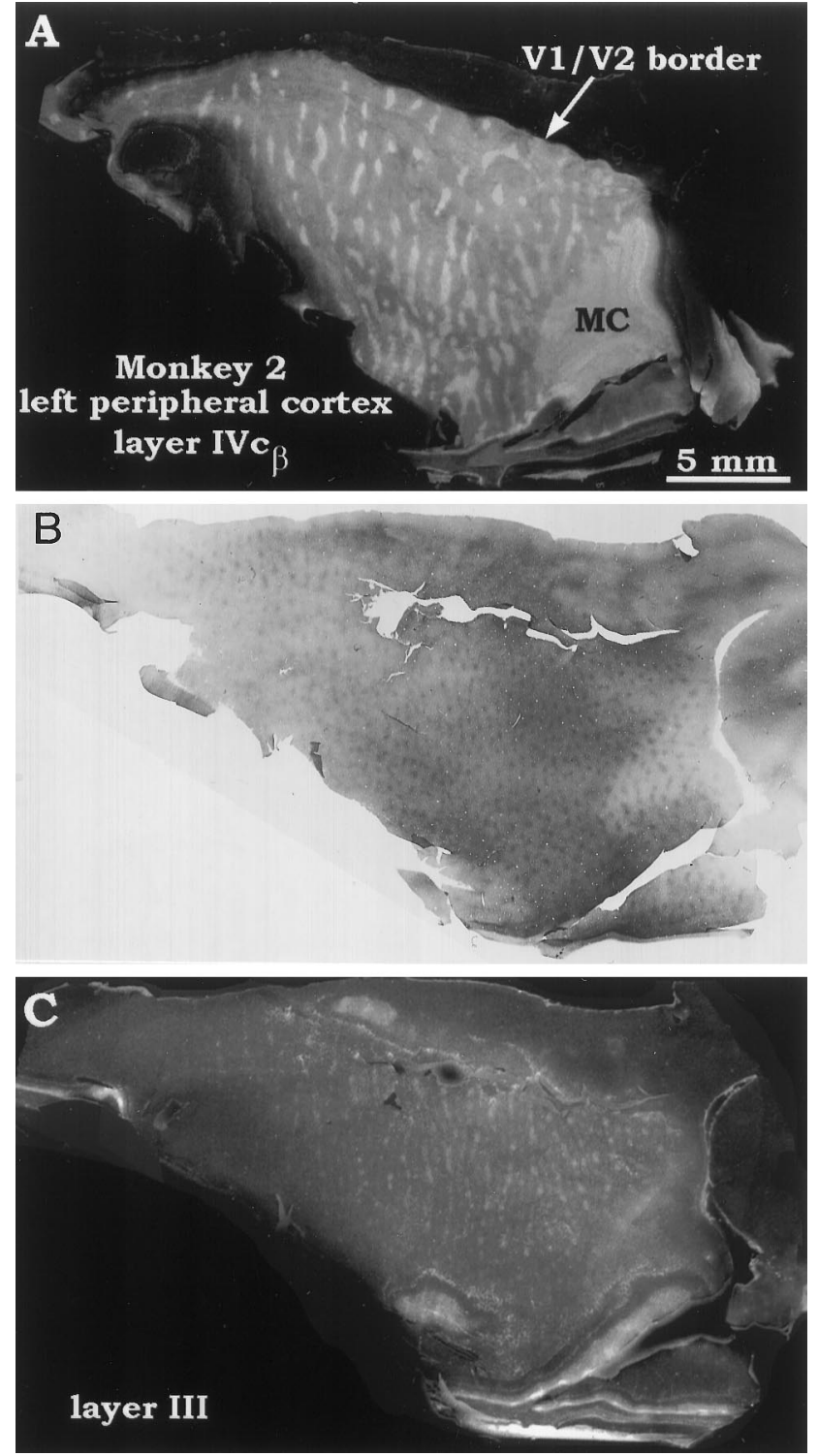

Figure 6. Monkey 2 (1 week suture). A, View of $\left[{ }^{3} \mathrm{H}\right]$ proline-labeled columns in the left peripheral cortex after injection of the deprived right eye. The columns are shrunken, but no more than on the operculum (compare with Fig. 4A). The labeled columns are more attenuated along the vertical meridian than the horizontal meridian. For retinotopic coordinates and orientation of this tissue segment within V1, see Figure 7. $M C$, Monocular crescent. $B$, Section from the upper layers of the same tissue block, showing the $\mathrm{CO}$ patches. $C$, Montage of the koniocellular projection to the CO patches in layer III, labeled by $\left[{ }^{3} \mathrm{H}\right]$ proline injection into the deprived right eye. At higher power, we verified that every $\mathrm{CO}$ patch in rows corresponding to the deprived columns in layer $\mathrm{IVc} \beta$ received a puff of $\left[{ }^{3} \mathrm{H}\right]$ proline label. Curiously, no puffs of proline label were seen in the monocular crescent representation, indicating that $\mathrm{CO}$ patches in this area receive no (or only a weak) thalamic projection.

deprived eye were best preserved in the foveal representation. This finding, also observed in a third monkey (Horton and Stryker, 1993a), led us to suggest in a preliminary report that ocular dominance columns within the foveal representation are less susceptible to shrinkage induced by early monocular deprivation (Horton and Stryker, 1993b). However, our view has changed after examining peripheral regions of striate cortex hidden within the calcarine fissure. Figure $6 A$ shows layer $I V c \beta$ from the peripheral left cortex of Monkey 2, contralateral to the deprived eye. 


\section{Left Striate Cortex}

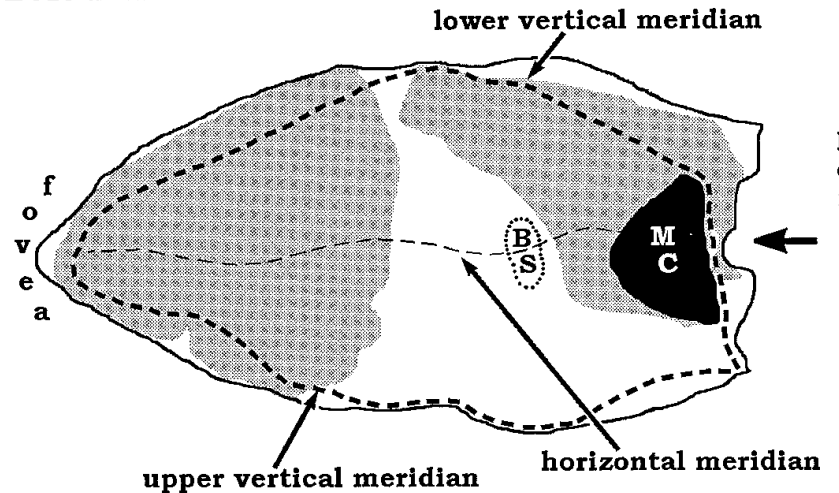

Right Striate Cortex

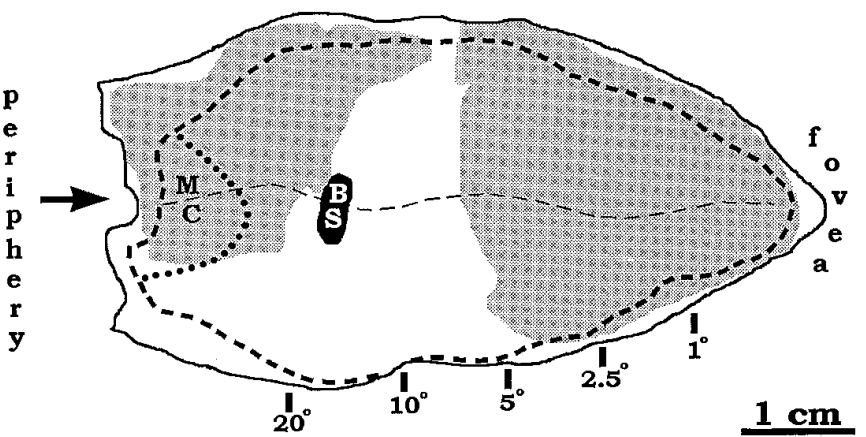

Figure 7. Monkey 2. Schematic drawing showing the retinotopic coordinates in unfolded, flattened macaque V1, to aid in interpretation of our flat-mount montages. The shaded area in the lateral portion of each cortex is the exposed, flat operculum of the occipital lobe, which represents the central $\sim 0^{\circ}-8^{\circ}$ (Fig. $4 A, B$ ). The shaded areas in the upper, medial portion of the left and right V1 are illustrated in Figures 6 and 8 , respectively. BS, Blind spot; $M C$, monocular crescent.

The location of this tissue segment within striate cortex is shown schematically in Figure 7 (left). The labeled columns of the deprived right eye were shrunken, but they still occupied $19 \%$ of layer IVc $\beta$. They were no more shrunken than the columns located within the foveal representation (compare Figs. $6 A$ and $4 A$ ). This finding invalidated our original notion, namely, that column shrinkage becomes increasingly severe across the cortex from the representation of the fovea to the periphery.

Figure $6 B$ shows the $\mathrm{CO}$ patches in the upper layers from the same block. In the monocular crescent, the CO patches were larger and more widely spaced (Horton, 1984). A montage of autoradiographs through layer III showed the projection to the patches of the injected right eye (Fig. $6 C$ ). Despite visual deprivation, all of the right eye's patches were well labeled, except in the monocular crescent. The absence of patch labeling in the monocular crescent was unexpected. We have since reviewed autoradiographs from previous experiments in four normal baby macaques that showed strong patch labeling after $\left[{ }^{3} \mathrm{H}\right]$ proline eye injection (Horton and Hocking, 1996a). In every animal, label in patches within the contralateral monocular crescent and the ipsilateral blind spot was absent or was much weaker than in nearby binocular cortex. We have no explanation for this observation.

For comparison, Figure 8 shows the matching piece of V1 from the right peripheral cortex, ipsilateral to the deprived eye (see Fig. 7 for orientation). In layer IVc $\beta$, the ocular dominance columns of the right eye were obliterated, except for a few islands near the vertical meridian (Fig. $8 A$ ). The deprivation effect was more striking than in the left peripheral cortex (compare Figs. $8 A$ and $6 A$ ). It was also more striking in layer $\operatorname{IVc} \beta$ than $\operatorname{IVc} \alpha$ (compare Fig. $8 A$ and $8 B$ ), confirming our observation from the operculum of the same animal (Fig. $4 C$ ). In the upper layers, the projection to the right eye's rows of patches (Fig. 8C) appeared intact. The labeling was indistinguishable from the pattern seen in normal macaques (see Fig. 5 in Horton and Hocking, 1996a). This result confirmed our findings in Monkey 0 (Fig. 1). Because the right eye's afferents to layer IVc $\beta$ were decimated, preserved input to right eye patches was often situated over regions of layer IVc $\beta$ surrendered to the left eye. This contrast in the laminar pattern of labeling within the same tissue block provided the most direct evidence that visual deprivation had affected the parvocellular projection more than the koniocellular projection.

\section{Monkey 3 (deprived at age 1 week)}

V1 was flat-mounted as a single piece of tissue to compare column shrinkage in the operculum and periphery in the same sections. The normal left eye was injected with $\left[{ }^{3} \mathrm{H}\right]$ proline, resulting in expanded columns of label interrupted by dark gaps belonging to the amblyopic right eye (Fig. 9). The labeling in the opercula was complementary to the pattern illustrated in Monkeys 1 and 2 . Again, a gradient in apparent column shrinkage occurred from the fovea to the periphery and from the vertical meridian to the horizontal meridian. The right eye's columns were slightly more shrunken in the ipsilateral cortex ( $8 \%$ of surface area) than the contralateral cortex (12\% of surface area; Table 2$)$. Overall, the degree of column shrinkage in Monkeys 1, 2, and 3 was comparable.

Although the right and left opercula looked quite similar in Monkey 3, in the periphery the pattern of labeling was quite different on the two sides. In the right hemisphere, the right eye's columns were nearly absent in the periphery, except near the vertical meridian (Fig. 9B,D). By contrast, in the left hemisphere the right eye's columns experienced a renaissance as they approached the monocular crescent (Figs. 9A,C). They were also larger near the horizontal meridian than the vertical meridian (the opposite of the pattern in the right hemisphere). These findings confirmed observations made in the peripheral fragments from Monkey 2 (Figs. 6, 8). They also confirmed a report by Hubel et al. (1977) that in peripheral calcarine cortex the ocular dominance columns appear more shrunken ipsilateral to the sutured eye (see their Fig. 21 $A, B)$.

We believe the key to this ipsi/contra discrepancy in column shrinkage lies with an observation by LeVay et al. (1985). They discovered that the columns of the ipsilateral eye become fragmented between the representation of the blind spot and the monocular crescent in peripheral cortex, especially along the horizontal meridian. We have confirmed this finding (Fig. 10A,B). In a complementary manner, the columns of the contralateral eye become larger and more confluent in this region. To determine how this asymmetry might be reflected in the appearance of the columns after visual deprivation, we simulated column shrinkage using a binary filter provided with the Mocha image analysis software (Jandel Scientific). This filter dilates a white object by converting a monolayer of pixels surrounding it from black to 

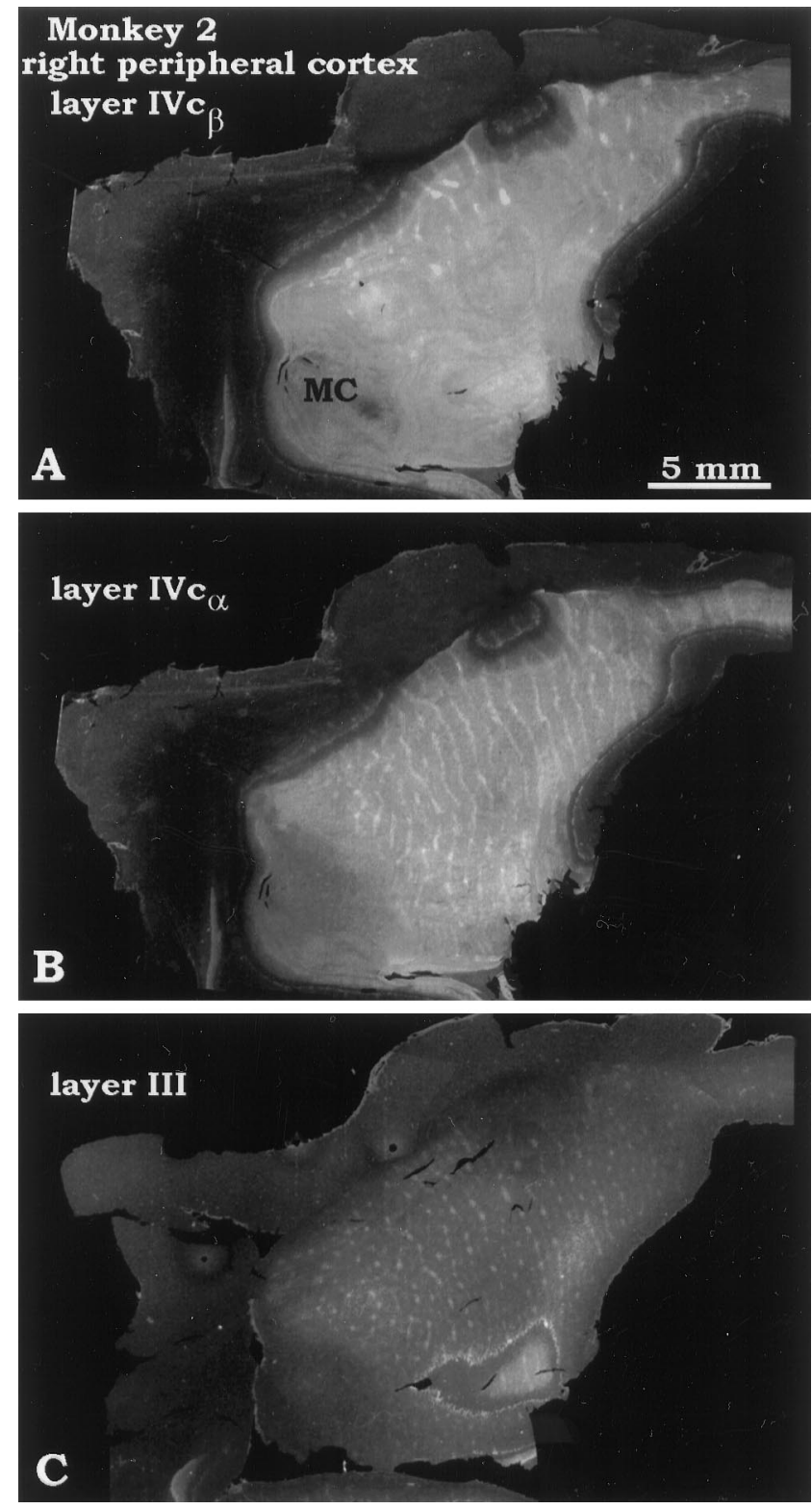

Figure 8. Monkey 2 (1 week suture). A, Montage of the right peripheral cortex, ipsilateral to the injected, deprived right eye (see Fig. 7 for location of this region). The labeled parvo columns were wiped out completely, except for a few remnants near the vertical meridian. $M C$, Monocular crescent. $B$, Montage of magno columns, showing much less shrinkage and fragmentation. In the monocular crescent, no columns were seen, because this area receives no projection from the ipsilateral eye. $C$, The patches in layer III situated within right eye columns (determined by alignment with panel B) received strong $\left[{ }^{3} \mathrm{H}\right]$ proline label from the right eye, despite virtual elimination of the projection to layer $\operatorname{IVc} \beta$ (compare $A, C$ ). This finding indicates that the koniocellular projection to the upper layers is more resistant to the effects of visual deprivation than the parvo projection to layer $\mathrm{IVc} \beta$.

white. After applying three iterations of this filter to a normal mosaic of columns, the resultant pattern bore a close resemblance to the columns in our monkeys deprived at age 1 week (compare Figs. $9 C, D$ and $10 C, D)$. In the peripheral right cortex, the right eye's columns (which were small to begin with) were extinguished, except along the vertical meridian. In the peripheral left cortex, the right eye's columns (which were big to begin with) fared much better, especially along the horizontal meridian.
The correlation between the computer model of column shrinkage and our anatomical data suggests that visual deprivation induces geniculocortical afferents to retract the same distance from the borders of the ocular dominance columns throughout primary visual cortex. The impression of greater shrinkage in the peripheral cortex ipsilateral to the deprived eye arises because there exists a normal, preexisting inequality in column widths in this region. There is no need to invoke a greater sensitivity of the ipsilateral eye to the effects of visual deprivation to explain why its columns appear smaller in the periphery after monocular suture.

In monkey 3, the blind spot representation of the left eye in the right visual cortex was shrunken (Fig. 9B,D). It measured only 4 $\mathrm{mm}^{2}$, compared with an average value of $10 \mathrm{~mm}^{2}$ in normal macaques (Horton and Hocking, 1996c). In this special region, geniculate afferents serving the right eye face no direct competition from the left eye because the left eye contributes no input. We expected this lack of competition to protect the blind spot representation from shrinkage. Nevertheless, it appears that the left eye's afferents, presumably serving retina surrounding the optic disk, invaded the disk's cortical representation. This puzzling result will be considered further in Discussion.

\section{Monkey 4 (deprived at age 3 weeks)}

Figure 11 shows flat-mounts prepared from Monkey 4, after $\left[{ }^{3} \mathrm{H}\right]$ proline injection into the the normal left eye. The intensity of autoradiographic labeling was greater in peripheral calcarine cortex than on the operculum (Kaas et al., 1976; Hendrickson et al., 1978; LeVay et al., 1978; Spatz, 1979). This tendency was observed in all of the flat-mounts, although it was more striking in some than in others. The reason is unclear, but it may reflect better tracer uptake by ganglion cells in peripheral retina. In addition, the contrast of the autoradiographic label was greater in the cortex ipsilateral to the injected eye in all animals (Shatz et al., 1977). In cats, this effect has been attributed to greater tracer spillover in the lateral geniculate body on the contralateral side (LeVay et al., 1978). However, in macaques it may indicate more complete segregation of the geniculate afferents serving the ipsilateral eye (Horton and Hocking, 1996a).

Eyelid suture at 3 weeks in Monkey 4 caused much less shrinkage of ocular dominance columns than eyelid suture at age 1 week in Monkeys 1, 2, and 3 (Table 2). On the opercula, the deprived columns remained coherent stripes rather than breaking into isolated fragments. The deprived right eye's columns occupied $9 \%$ less surface area on the ipsilateral operculum compared with the contralateral operculum. This imbalance was also marked in peripheral cortex. On both opercula, the deprived columns were slightly wider in the foveal region and along the V1/V2 border, echoing the tendency seen in Monkeys 1, 2, and 3. The blind spot was also shrunken in the ipsilateral cortex (Fig. 11B), replicating the finding in the ipsilateral cortex of Monkey 3.

\section{Monkey 5 (deprived at age 5 weeks)}

This monkey was the oldest and largest of our cohort but, ironically, it had the smallest V1 (Table 2). On the left side, the calcarine fissure did not unfold completely, leaving $\sim 100 \mathrm{~mm}^{2}$ buried (Fig. 12). However, on the right side we obtained a complete reconstruction, and the surface area of striate cortex was barely $1000 \mathrm{~mm}^{2}$. The shrunken columns of the deprived right eye were unlabeled, because $\left[{ }^{3} \mathrm{H}\right]$ proline was injected into the normal left eye. In the left operculum, the column shrinkage was equal to the degree seen in the left operculum of Monkey 4, sutured at 3 weeks (compare Figs. $12 A$ and $11 A$ ). However, in the left periph- 

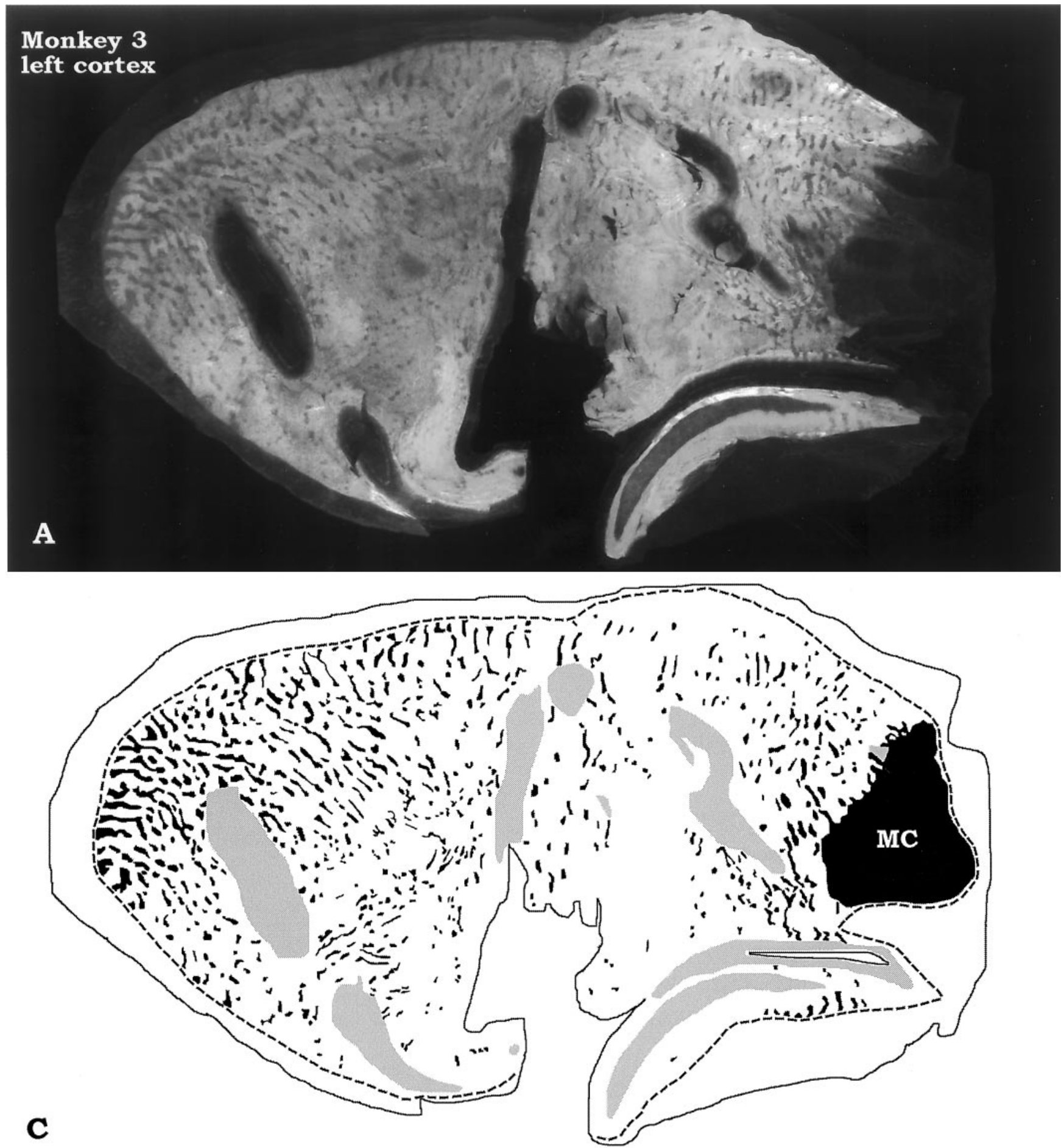

Figure 9. Monkey 3 (1 week suture). $A, B$, Autoradiographic montage of layer IVc $\beta$ after deprivation of the right eye. The normal left eye was injected with $\left[{ }^{3} \mathrm{H}\right]$ proline. The deprivation effect was severe and complemented the findings obtained in Monkeys 1 and 2 after injection the deprived eye. $C, D$, Drawing of the columns in $A$ and $B$. This cortex was unusually large and did not flatten well. Despite the blemishes, one can appreciate that more unlabeled (right eye) columns survived in the left periphery than in the right periphery. The border of the monocular crescent could not be discerned in the right cortex, because the ocular dominance columns of the right eye were extinguished completely in the periphery. In the left cortex, the boundary of the blind spot representation of the right eye was uncertain, for the same reason. In the right cortex, the blind spot $(B S)$ representation of the left eye was shrunken. MC, Monocular crescent. Figure continues.

eral cortex the column shrinkage in Monkey 5 was less severe than in the corresponding region of Monkey 4. This point can be appreciated by observing that more black, unlabeled territory is present between the blind spot and monocular crescent in Figure
$12 A$ than in Figure $11 A$. Comparison of Monkeys 4 and 5 illustrates that the relative column shrinkage in central versus peripheral cortex can vary from animal to animal.

In the right operculum of Monkey 5, the column shrinkage was 

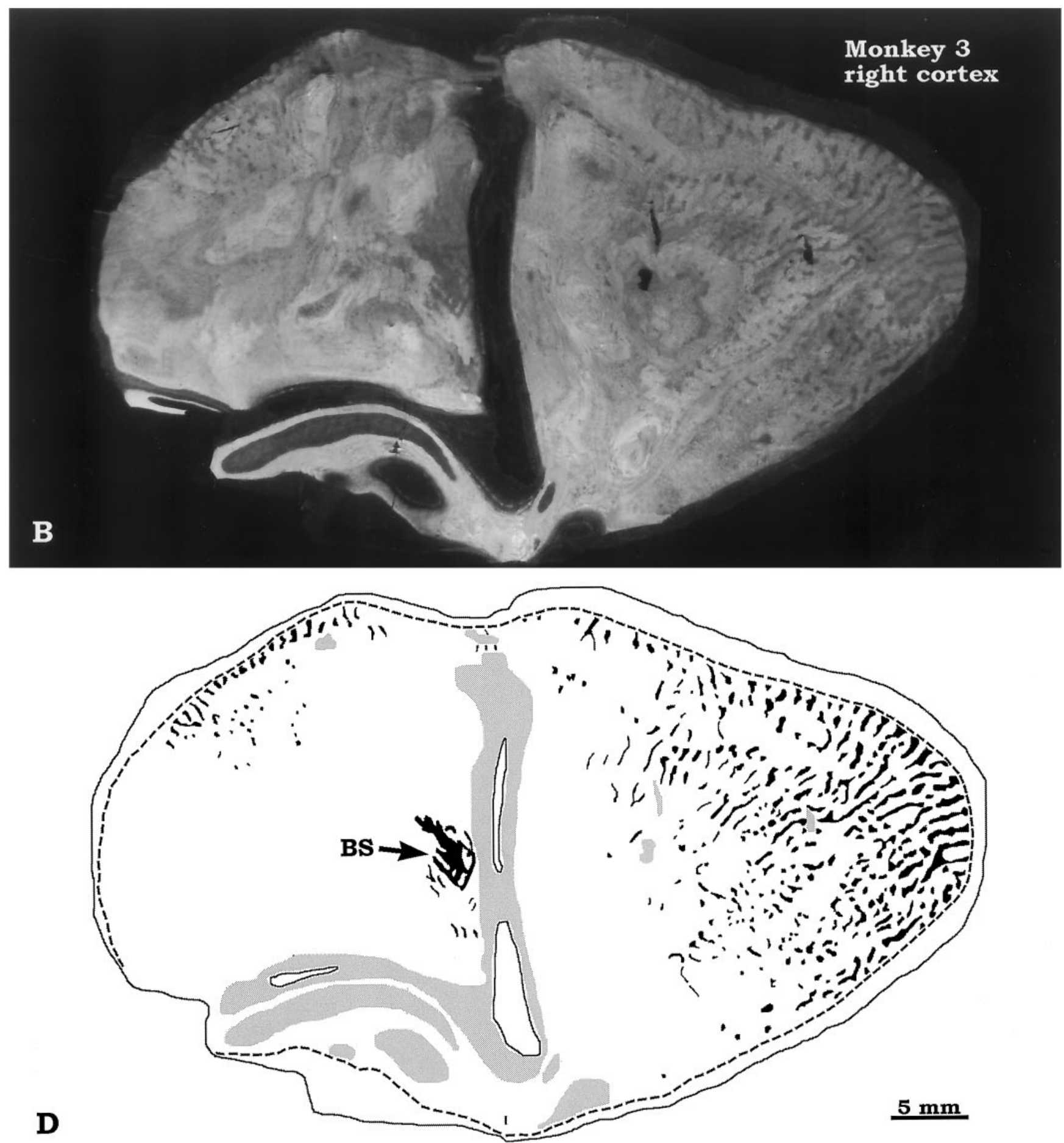

Figure 9 continued.

less than in the right operculum of Monkey 4 (Table 2). Consequently, for Monkeys 4 and 5 the degree of column shrinkage was equal for the left opercula and different for the right opercula. This discrepancy is addressed in Discussion.

\section{Monkey 6 (deprived at age 5 weeks)}

Monkey 6 was deprived at age 5 weeks, repeating the experiment in Monkey 5. Tracer injection into the normal left eye revealed a more intricate mosaic than in Monkey 5, with a large number of column pairs (145) along the V1/V2 border (Fig. 13). In Macaca fascicularis we have observed substantial variability in the periodicity of ocular dominance columns (Horton and Hocking, 1996c). The results summarized in Table 2 indicate that a similar degree of variability is present in M. mulatta.

In Monkey 6, the shrunken columns of the right eye occupied less territory in the right operculum $(37 \%)$ compared with the left operculum (43\%). In the right operculum, the expanded columns of the left eye tended to melt together, creating numerous islands of shrunken black columns (Fig. 13B). In the left operculum, the 


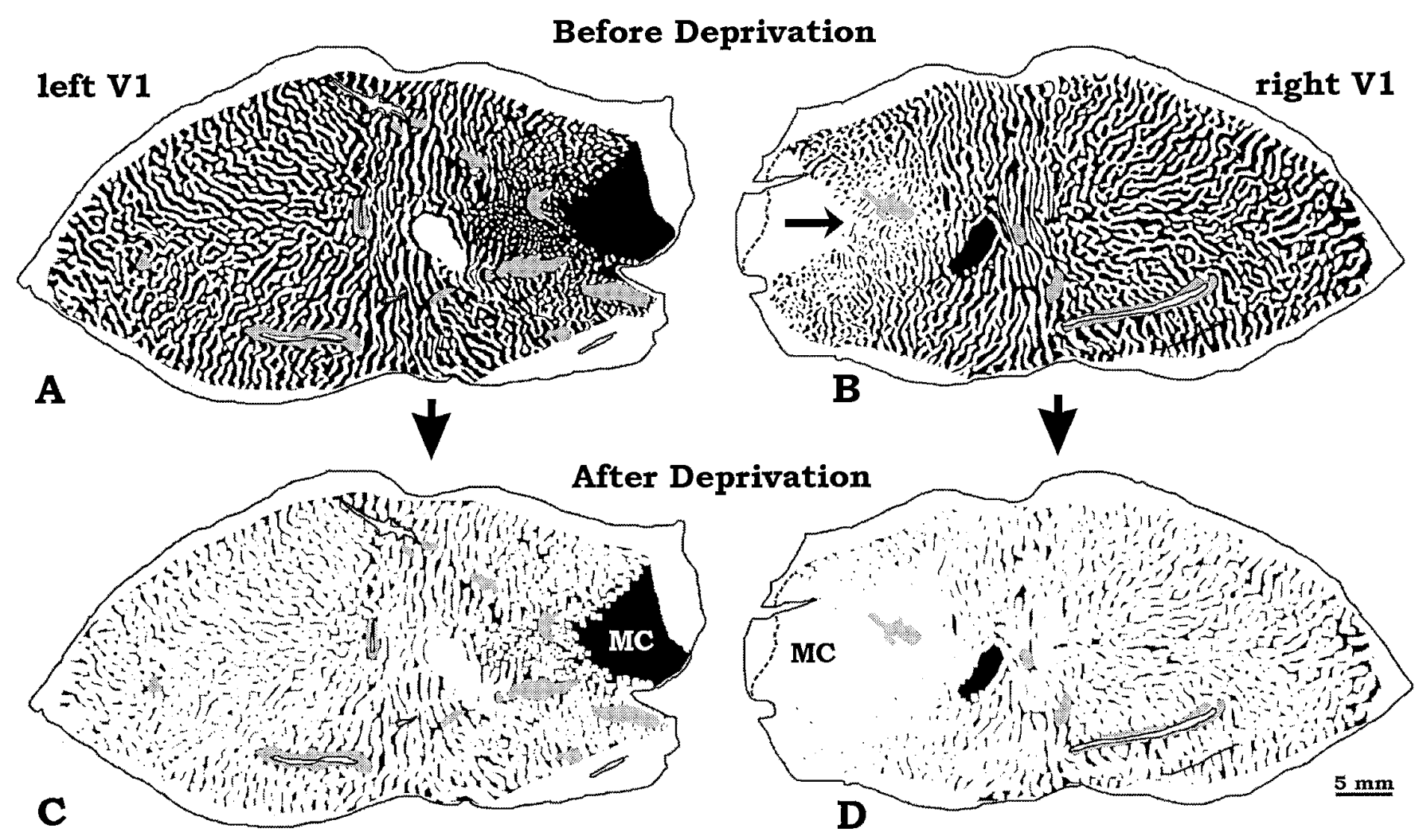

Figure 10. A, B, Pattern of ocular dominance columns from a normal monkey (reproduced from Fig. 3, $B$ and $E$, in Horton and Hocking, 1996c). Between the blind spot and the monocular crescent, the ipsilateral eye's columns become relatively small and fragmented, especially along the horizontal meridian [e.g., note the diminutive black columns of the right eye in $B$ near the monocular crescent (arrow)]. The converse occurs to the contralateral eye's columns: they become large and confluent, engulfing the ipsilateral eye's columns. $C, D$, Shrinkage of the black columns, modeled using Mocha image analysis software, by switching the sign of pixels along the borders of the white columns from black to white. For this simulation, 1 pixel $=58 \mu \mathrm{m}$; the average width of ocular dominance columns before application of the dilation filter was $\sim 8$ pixels. After three iterations of the filter, the columns resembled closely the pattern of shrinkage seen after visual deprivation at age 1 week (see Fig. 9).

left eye's columns did not merge to the same degree because they occupied relatively less territory. This asymmetry between hemispheres in column areas belonging to each eye contrasted with the findings in Monkey 5, also sutured at age 5 weeks. In this animal, the deprived right eye occupied the same territory in the ipsilateral $(36 \%)$ and the contralateral $(35 \%)$ opercula.

In Monkey 6 (sutured at 5 weeks), the right eye's columns were less shrunken than in Monkey 4 (sutured at 3 weeks). This difference held for the opercular and peripheral cortex in both hemispheres (Table 2), supporting the notion that susceptibility to column shrinkage declines with suture at a later age.

\section{Monkey 7 (deprived at age 7 weeks)}

The deprivation effect in this monkey was mild (Table 2), indicating that by age 7 weeks the susceptibility of the ocular dominance columns to shrinkage had declined still further (Fig. 14). The animal had an enormous V1 on each side, averaging nearly 1600 $\mathrm{mm}^{2}$. Comparison of Figures 12-14 provides a vivid impression of the range of V1 areas and column periodicities found in this study. We corroborate Van Essen et al. (1984), who reported twofold variation in macaque V1 surface area and no obvious correlation with body weight.

\section{Monkey 8 (deprived at age 12 weeks)}

This animal showed no shrinkage of ocular dominance columns after deprivation of the right eye starting at age 12 weeks (Fig. 15). Column areas for the left and right eye were nearly equal on the opercula (Table 2). In the periphery, the ipsilateral eye occupied less territory on each side, as in normal animals.

LeVay et al. (1980) reported slight shrinkage of the ocular dominance columns in a monkey sutured at age 10 weeks, but no shrinkage in another monkey sutured at age 7 months. The lack of column shrinkage in Monkey 8 allows one to bracket the end of the critical period more precisely. In macaques, the susceptibility of ocular dominance columns to shrinkage induced by monocular suture ends between age 10 and 12 weeks.

\section{DISCUSSION}

\section{Timing of the critical period}

Hubel, Wiesel, and LeVay's $(1977,1980)$ images of shrunken ocular dominance columns provided the first convincing evidence that anatomical connections in the developing primate brain can be altered by abnormal sensory stimulation during a critical period after birth. In their original discussion of this phenomenon, Hubel and Wiesel (1970) invoked the work of Lorenz (1935) on imprinting behavior in birds. In ducklings, the "following response" becomes fixed during a brief critical period that peaks at $17 \mathrm{hr}$ after hatching. Ducklings show little interest in following decoys before $12 \mathrm{hr}$ or after $24 \mathrm{hr}$ (Hess, 1973). By analogy, Hubel and Wiesel (1970) reported in kittens that susceptibility to eyelid closure begins suddenly near the start of the fourth week and then declines after the eighth week. From this finding, they concluded that 
the kitten's visual system is too immature for monocular deprivation to have much effect during the first weeks of life. In support of this notion, Olson and Freeman (1980) found no change in the ocular dominance profiles of cortical neurons in kittens sutured from day 8 to day 19. Thereafter, just a few days of monocular deprivation were sufficient to produce a major shift in ocular preference.

In an initial report concerning macaques, Hubel et al. (1977) suggested that column shrinkage was more severe after lid suture at age 2 weeks compared with 3 weeks. In their definitive study, LeVay et al. (1980) later retracted this observation by concluding: "deprivation begun at any age from birth to about 6 weeks had approximately the same effect." This result might be explained if macaques, like cats, were relatively immune to the effects of monocular deprivation for the first few weeks after birth. However, LeVay and coworkers found severe column shrinkage in a monkey sutured at $2 \mathrm{~d}$ and examined at $24 \mathrm{~d}$, nullifying this interpretation.

Repeating the experiments by LeVay and coworkers, we have found greater shrinkage and fragmentation of ocular dominance columns with lid suture starting at age 1 week compared with later dates. For example, the column shrinkage after suture at age 1 week was approximately twice as severe as the shrinkage after suture at age 5 weeks (Table 2). From these data, we conclude that macaques are highly sensitive to the effects of visual deprivation within a week of birth (and probably even sooner). Unlike kittens, there is no significant delay after birth in the onset of the critical period.

In making these new observations, we have benefited from information and methods not available to Hubel et al. when they performed their classic experiments. As LeVay et al. (1985) discovered only later, the ocular dominance columns in normal animals show marked regional variation in width (e.g., the ipsilateral columns become broken and narrowed in the periphery). To make valid comparisons, it is crucial to reconstruct wide expanses of cortex to obtain a coherent view of the shrunken columns or at least to survey the same region in every animal. LeVay et al. (1980) examined small fragments of tissue, averaging only $\sim 5 \%$ of the total V1 surface area, from different regions in each animal. Improved methods for flat-mounting the cortex and for preparing computer montages have made it easier to gauge the effects of visual deprivation more accurately (Horton, 1984; Olavarria and Van Sluyters, 1985; Tootell and Silverman, 1985; Anderson et al., 1988; Rosa et al., 1988; Florence and Kaas, 1992; Hata and Stryker, 1994; Horton and Hocking, 1996c).

\section{Gradients in column shrinkage}

Previous investigators have reported greater shrinkage of ocular dominance columns ipsilateral to the sutured eye (Hubel et al., 1977; LeVay et al., 1980) or in peripheral cortex as opposed to opercular cortex (Swindale et al., 1981). We confirm these tendencies but attribute them to preexisting inequalities in column widths present in normal mosaics before the onset of visual deprivation. For example, the smallest columns are located in the peripheral cortex, serving the ipsilateral eye. After monocular deprivation, these columns become the most severely reduced in size. Visual deprivation seems to subtract the same amount of territory from all of the columns throughout any given mosaic, at least to a first approximation. This impression was supported by simulation of column shrinkage using the dilation filter available with the Mocha image analysis program. Stripping pixels evenly from one set of columns and adding them to the other set created a mosaic of artificially shrunken columns that resembled closely those from animals deprived by lid suture (compare Figs. 9 and 10).

The most direct way to prove that visual deprivation reduces columns everywhere by the same amount would be to compare mosaics in the same animal, before and after visual deprivation. This is impossible, except with optical imaging. Unfortunately, this technique cannot image buried cortex and it renders less distinct columns than $\left[{ }^{3} \mathrm{H}\right]$ proline autoradiography. Until a better method becomes available, we shall be forced to rely on comparisons between different animals-normal and deprived. This approach is dogged by marked intrinsic variability from one animal to the next. A few examples suffice to illustrate how this variability complicated the interpretation of our data. In normal macaques, we reported recently that ocular dominance columns are wider in the foveal representation and along the V1/V2 border (Horton and Hocking, 1996c). In our mosaics, this tendency accounts for the wider appearance of the columns in these regions after monocular deprivation (e.g., see Figs. 2, 4, 9, 11-15). However, enlargement of the columns in the foveal region and along the $\mathrm{V} 1 / \mathrm{V} 2$ border is quite variable in normal animals and in deprived animals. This variation makes it difficult to exclude the possibility that we suggested originally, namely, that columns in these regions are less susceptible to shrinkage from monocular deprivation (Horton and Stryker, 1993b).

The second example concerns the degree of column shrinkage ipsilateral versus contralateral to the deprived eye. In binocular V1 of normal macaques, the ipsilateral eye's columns occupy less territory overall $(43.2 \pm \mathrm{SD}, 2.4 \%, n=12)$ than the contralateral eye's columns (56.8\%; calculated from Table 2 in Horton and Hocking, 1996c). Obviously, if the ipsilateral eye's columns occupy less area in normal animals, they will appear more shrunken in deprived animals. The predominance of the contralateral eye is more pronounced in peripheral cortex (mean ratio 63:37) than in opercular cortex (mean ratio 52:48) (Horton and Hocking, 1996c). In normal animals, there is a surprising range in the contralateral eye/ipsilateral eye ratio of opercular column areas, from 54:46 to 48:52. In peripheral cortex, this variation is even greater. The ratio can also differ between hemispheres in the same animal. This fluctuation is sufficient to account for the wide range that we measured in the ratio of contralateral eye/ipsilateral eye column areas (Table 2) and for the fact that at least one animal had more shrunken columns in the operculum contralateral to the deprived eye (e.g., Monkey 2, Fig. 4).

Finally, there is real variability in column shrinkage from animal to animal. Monkey 1 had less shrinkage than Monkey 2, despite suture at the same age. Monkey 4 (sutured at 3 weeks) had more column shrinkage in the right operculum than Monkey 5 (sutured at 5 weeks), but the same shrinkage in the left operculum. This variability can mislead, and it undoubtedly helped persuade LeVay et al. (1980) that suture at different dates results in the same degree of column shrinkage. In principle, variability can be overcome by performing large numbers of experiments and then subjecting the data to statistical analysis. However, this approach is not practical for primate studies, which are inevitably limited to a handful of animals. We reduced variability by using time-mated animals and sutured enough animals at 1 week and 5 weeks to convince ourselves that a genuine decline occurred in the susceptibility to column shrinkage over this interval. The study by LeVay et al. (1980) was limited by their use of newborns of unknown gestational age and by the fact that they tested only one animal at each suture date. 

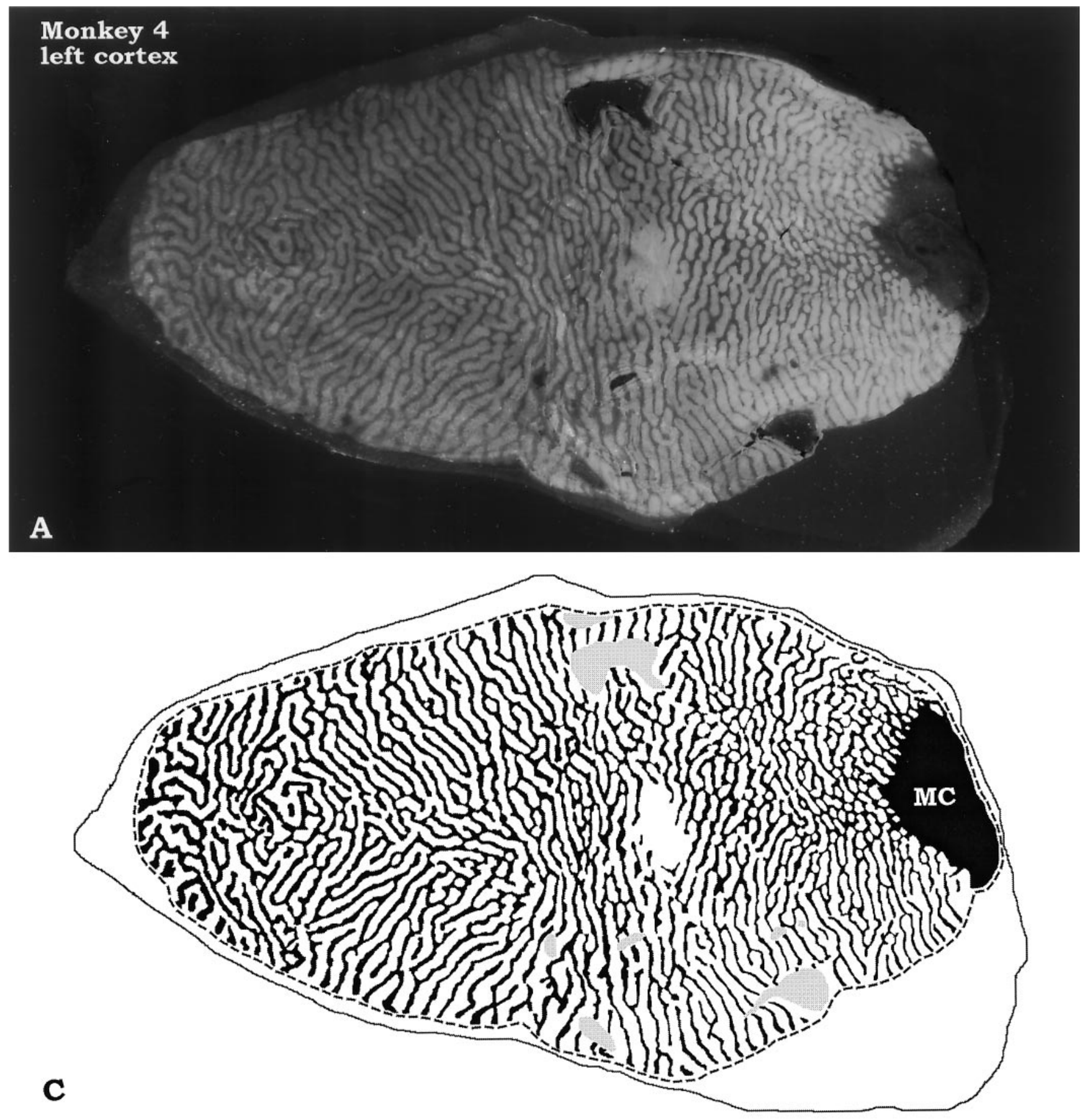

Figure 11. Monkey 4 (3 week suture). A, B, Autoradiographic montage of layer IVc $\beta$, showing shrinkage of the unlabeled columns of the deprived right eye. There was less column shrinkage than after deprivation starting at age 1 week (compare with Fig. 9). As in all autoradiographs, the columns were labeled more intensely in the peripheral cortex than on the operculum and were labeled more crisply in the cortex ipsilateral to the injected eye. $C, D$, Drawings of the columns showing that after deprivation the columns appeared widest in the foveal region and along the V1/V2 border (dashed line) on the operculum. In the right cortex, the blind spot representation was shrunken, as in Figure $9 D$. Note also that in the right periphery, the shrunken black columns got progressively thinner moving from the vertical meridian to the horizontal meridian. In the left periphery, the opposite occurred: the black columns got wider moving from the vertical meridian to the horizontal meridian, and they were less shrunken overall. These differences, also seen in Monkeys 2 and 3, occur because in normal monkeys the columns of the ipsilateral eye become attenuated along the horizontal meridian in the periphery (see Fig. 10). Figure continues.

\section{Shrunken ocular dominance columns coalesce around CO patches}

In the foregoing discussion, we concluded that visual deprivation attenuates columns equally throughout striate cortex, at least to a first approximation. We added the proviso because severely de- prived animals exhibit a curious clumping of surviving column remnants that cannot be explained by equal shrinkage along column frontiers. As columns become fragmented, they coalesce in layer $\operatorname{IVc} \beta$ in register with $\mathrm{CO}$ patches (or short strings of patches) in the upper layers. We never observed a column rem- 

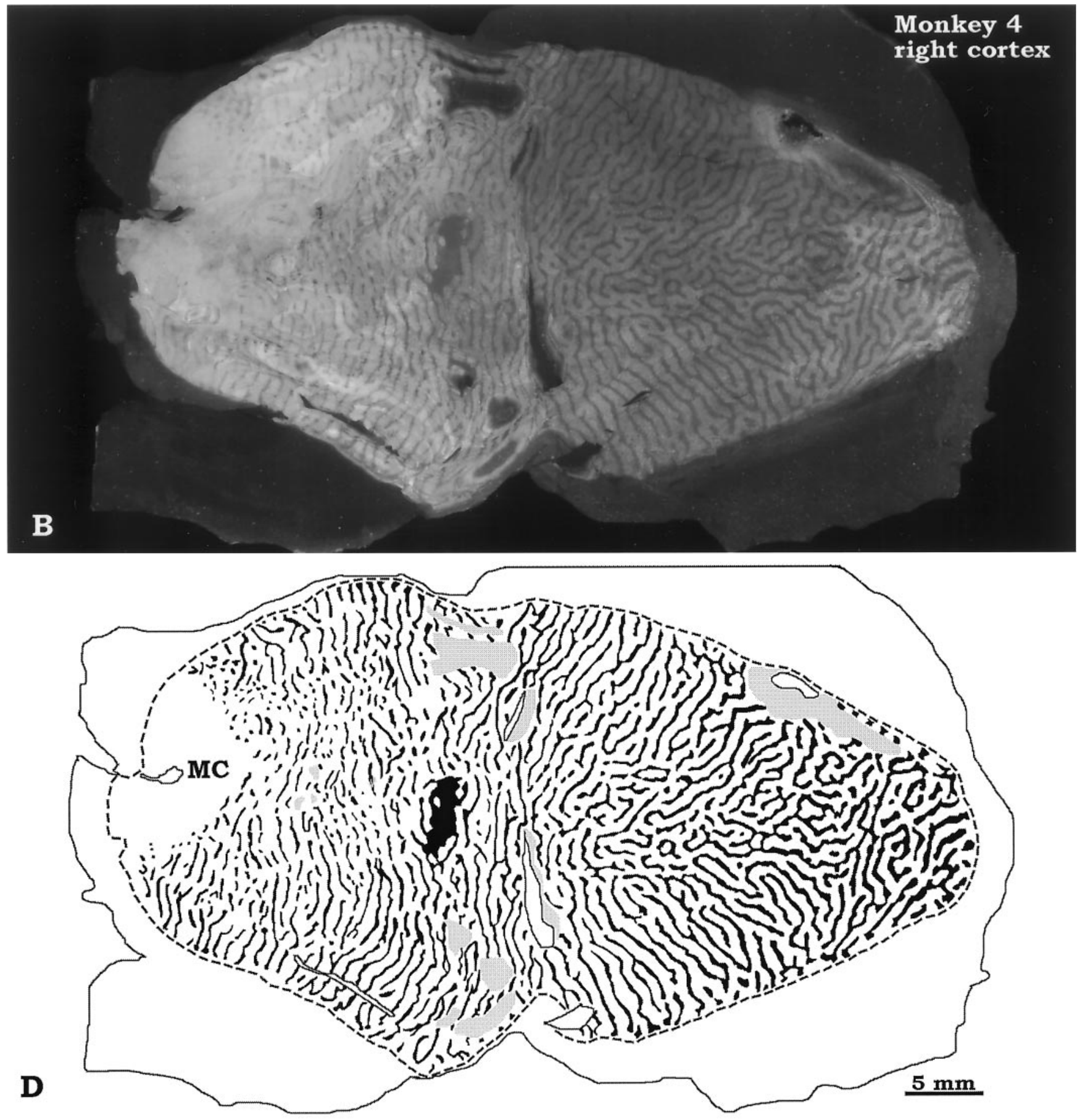

Figure 11 continued.

nant in layer IVc $\beta$ without an associated $\mathrm{CO}$ patch. In a sense, this result was not surprising, because columns shrink by erosion from the edge to the center, where $\mathrm{CO}$ patches are located (Horton and Hubel, 1981; Horton, 1984). Patches also have a tendency to be located at column bifurcations and excrescences, where ocular dominance columns are wider to begin with and, therefore, more likely to survive after shrinkage (Horton, 1984). In peripheral cortex of normal animals, where ocular dominance columns of the ipsilateral eye become naturally fragmented, each fragment is aligned with a CO patch (J. Horton and D. Hocking, unpublished observations). Evidently, in macaques the association between ocular dominance columns and $\mathrm{CO}$ patches remains strong, even after columns become fragmented by visual deprivation. By contrast, in normal squirrel monkeys the ocular dominance columns and CO patches are unrelated (Horton and Hocking, 1996b).

\section{Differing susceptibility of parvo, magno, and konio projections}

The geniculate projection to layer IVc $\beta$ was more shrunken than the projection to layer IVc $\alpha$ (Figs. 4, 8), indicating that the parvocellular channel conveying fine spatial information to the cortex is affected more by visual deprivation than the magnocel- 

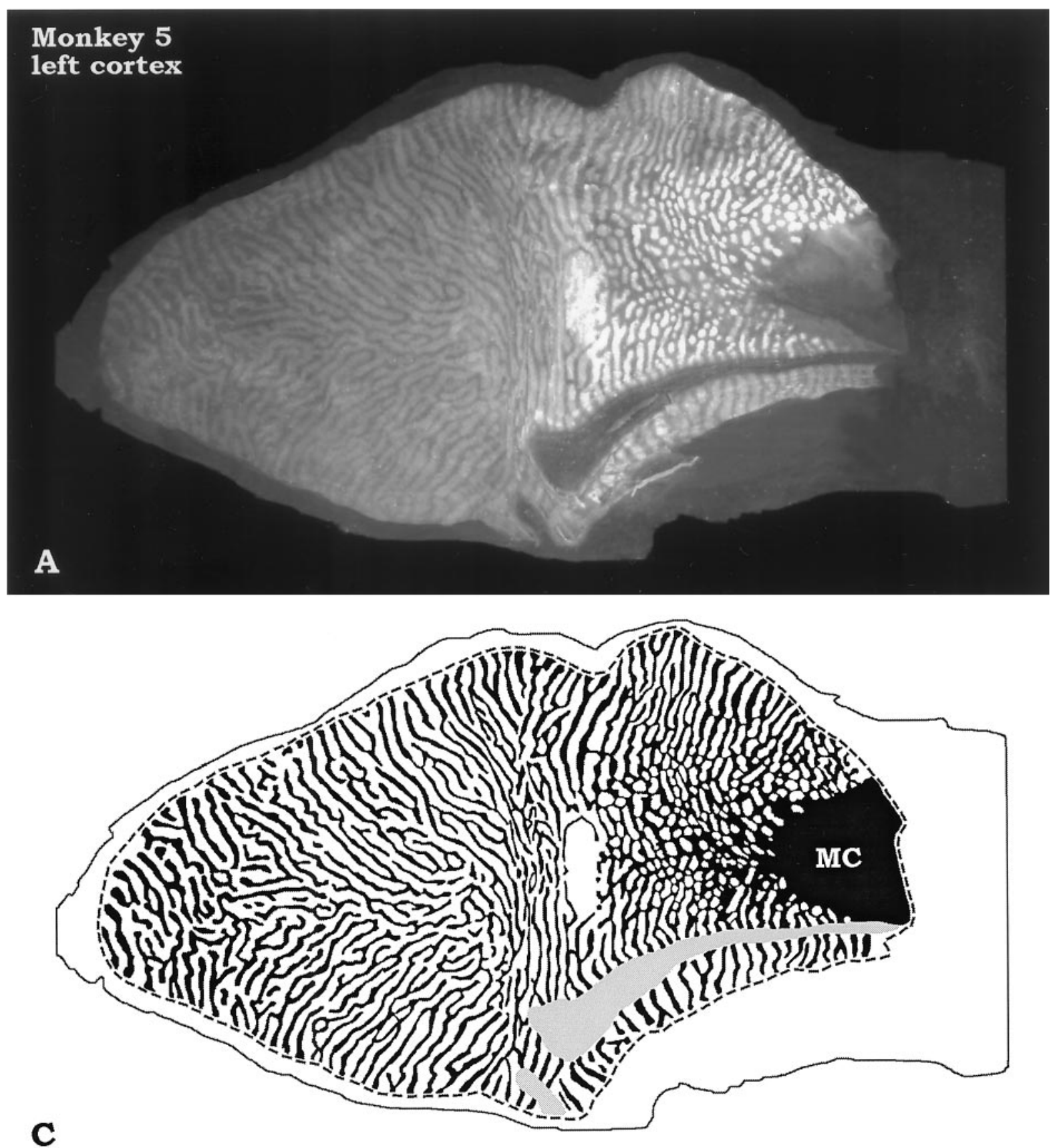

Figure 12. Monkey 5 (5 week suture). $A$, Montages of layer $\operatorname{IVc} \beta$ after injection of the normal left eye. In the left operculum, the column shrinkage equaled the shrinkage seen in the left operculum of Monkey 4 (Fig. 11A), despite starting visual deprivation 2 weeks later. However, in the left periphery the deprivation effect was less marked. $B$, The right operculum showed a comparable deprivation effect, although the columns were less distinct. The deprivation effect in the right operculum was less pronounced than in the right operculum of Monkey 4 , sutured at 3 weeks. $C$, $D$, Drawings of the montages in $A, B$. The calcarine fissure did not open completely in the left cortex. Figure continues.

lular channel. This conclusion supports previous findings in macaques raised with blurred vision in one eye from atropine (Hendrickson et al., 1987; Movshon et al., 1987). It is also consistent with the observation in a reverse-sutured monkey that column plasticity ends first for the magnocellular projection (LeVay et al., 1980).

The CO patches in the upper layers receive a direct thalamic projection (Livingstone and Hubel, 1982; Fitzpatrick et al., 1983; Weber et al., 1983; Horton, 1984; Itaya et al., 1984). Recent evidence suggests that this projection arises from the koniocellular laminae of the lateral geniculate body (Hendry and Yoshioka, 1994). In our first experiment (Fig. 1), this projection appeared normal, despite eyelid suture at age 1 week. This result might be explained if the open eye's koniocellular afferents invaded the deprived eye's patches. However, in another monkey we showed by ocular injection of $\left[{ }^{3} \mathrm{H}\right]$ proline that the projection indeed arises from the deprived eye (Figs. 6C, 8C). Recently, we have learned that konio cells in the lateral geniculate body are much less shrunken by visual deprivation than parvo or magno cells (S. H. Hendry, personal 

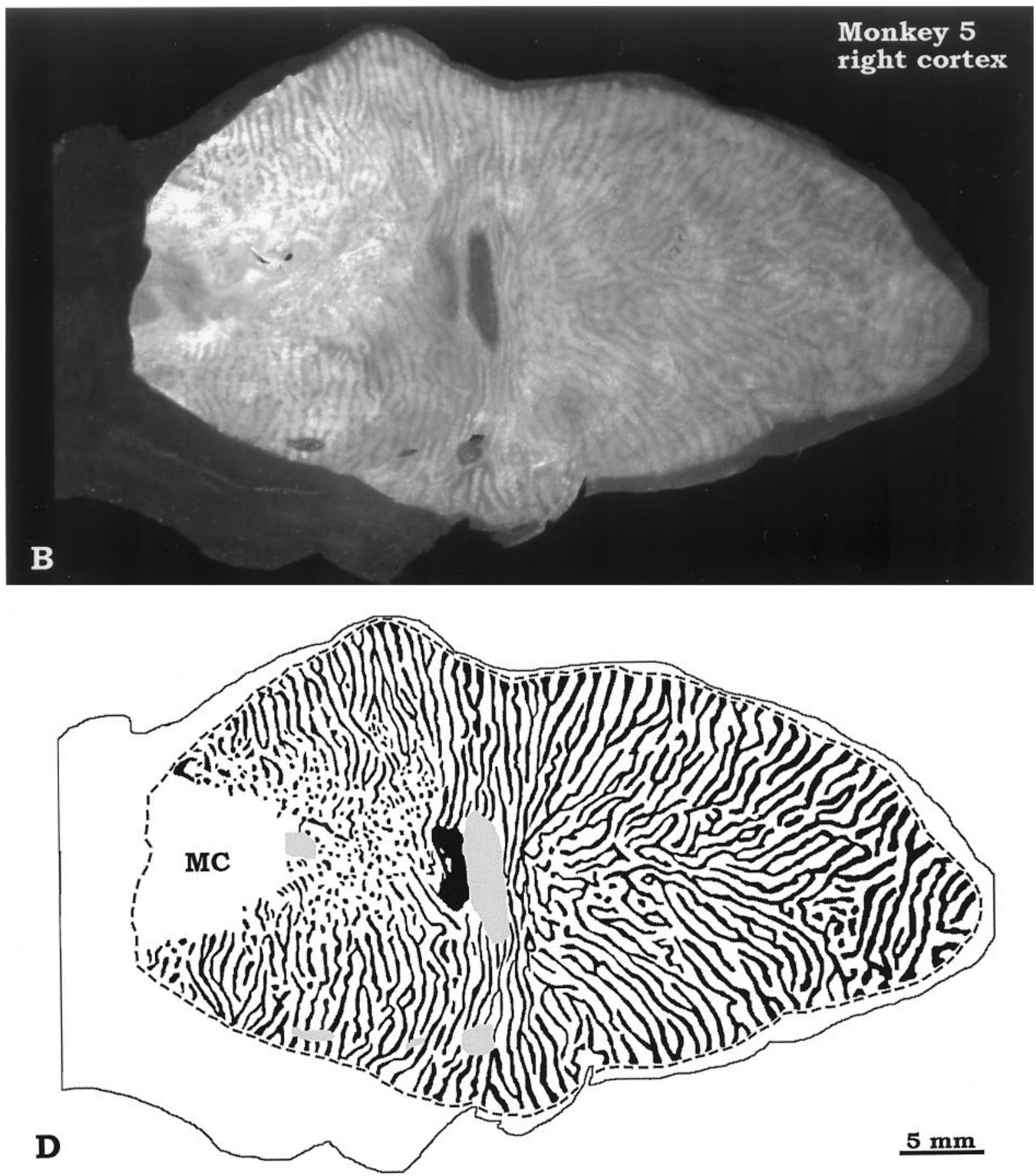

Figure 12 continued.

communication). This finding is consistent with our observation of a spared koniocellular projection to the $\mathrm{CO}$ patches in deprived animals. It has been observed that the critical period for monocular deprivation persists for up to 1 year in the upper layers of the cortex (LeVay et al., 1980; Daw et al., 1992). We are unsure how to reconcile this fact with a shorter critical period for the koniocellular projection than the parvocellular projection. Perhaps cells in patches differ from cells between patches in their susceptibility to monocular deprivation.

The significance of these differences among parvo, magno, and konio projections in their susceptibility to visual deprivation is unclear. Macaques reared with early monocular suture have gross light perception only (Von Noorden et al., 1970; Baker et al., 1974; Sparks et al., 1986), suggesting that all three perceptual channels are cut off at some point between striate cortex and the locus of visual consciousness.

\section{Mechanism of binocular competition}

The geniculocortical afferents serving each eye are intermingled in layer IVc of fetal macaques (Rakic, 1977). Ocular dominance columns begin to emerge during the last few weeks of gestation and appear well formed at birth (Rakic, 1977; Horton and Hocking, 1996a). At the time of lid suture in our experiments, the geniculocortical afferents were segregated almost completely. 


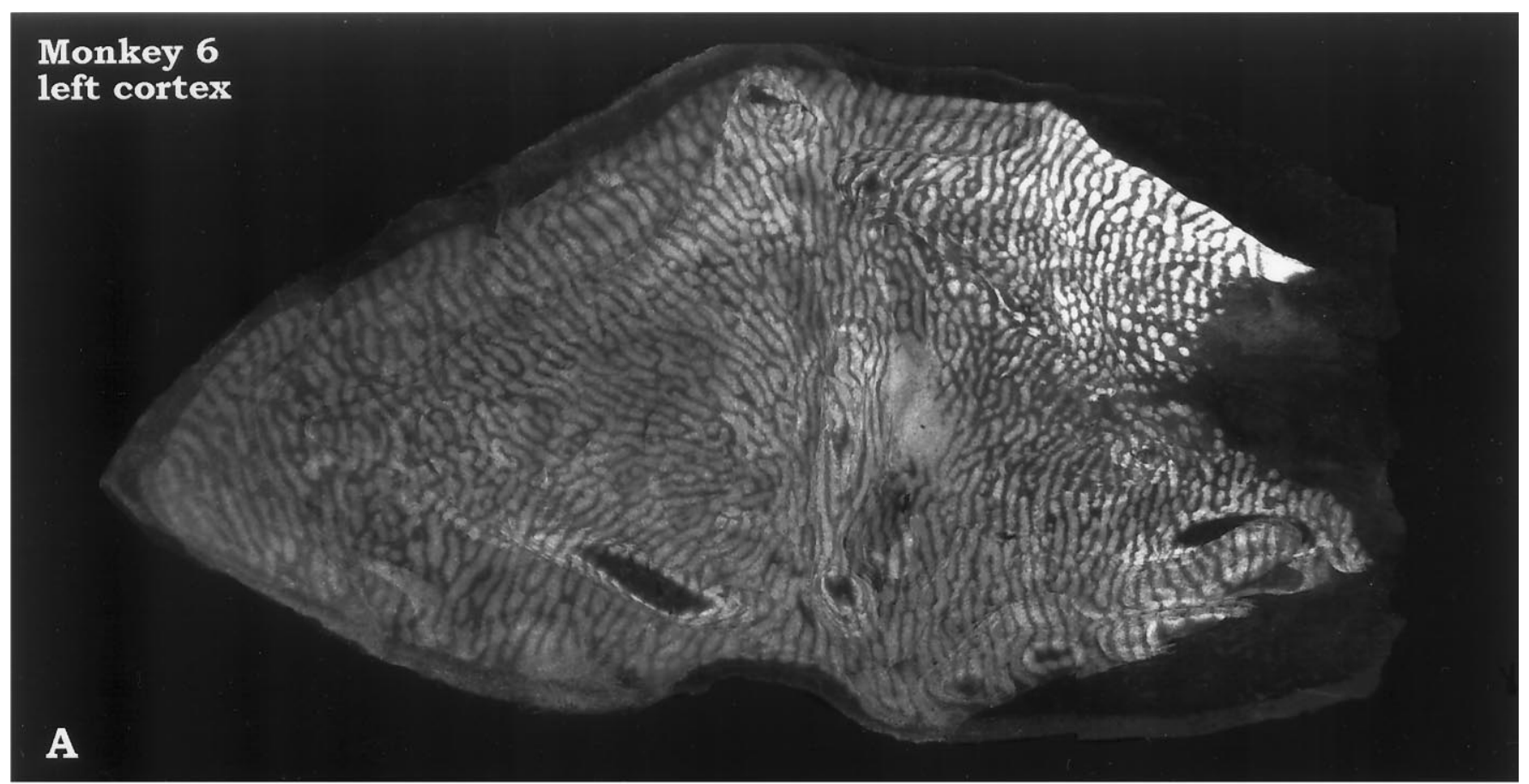

C

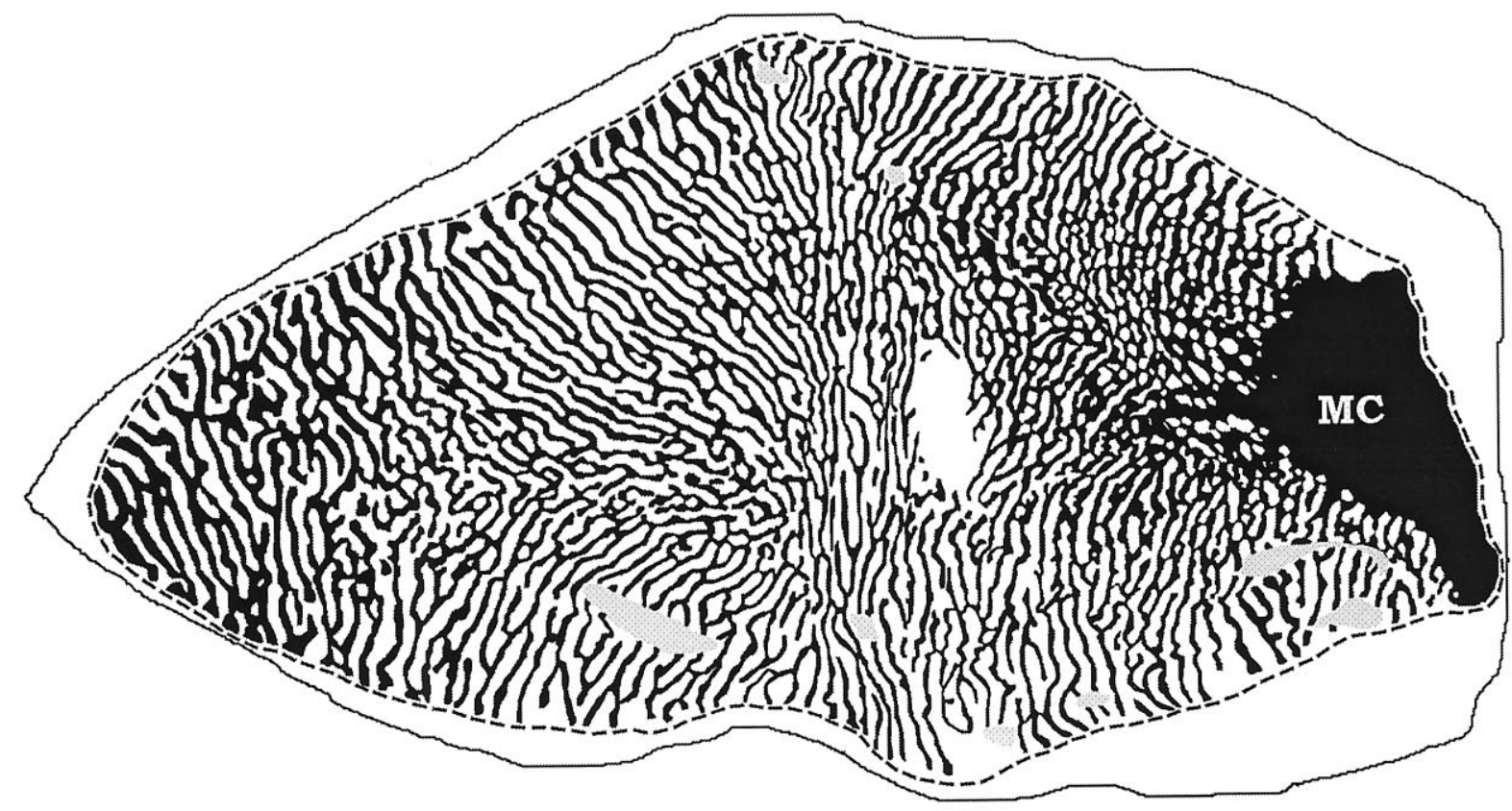

Figure 13. Monkey 6 (5 week suture). Montages of layer IVc $\beta$ after injection of the normal left eye show less shrinkage of the right eye's columns than in Monkey 4, sutured at 3 weeks. This animal had small cortices with a large number of column pairs. On the right operculum, the expanded columns of the left eye merged together, fragmenting the right eye's columns into islands, especially along the horizontal meridian. This effect did not occur on the left side, because the columns of the right eye occupied relatively more territory. Note that the largest column remnants serving the right eye were found in the foveal regions and in the left periphery. Figure continues.

Therefore, column shrinkage and expansion occurred principally by retraction and sprouting of fibers along the borders between columns.

Guillery and Stelzner (1970) reported that cells within the monocular segment of the kitten's lateral geniculate body are spared atrophy after eyelid suture, because their cortical arbors face no competition from the open eye. Although later studies showed some shrinkage in the monocular segment (von Noorden and Middleditch, 1975; Von Noorden et al., 1976), presumably from disuse, this area is less affected by deprivation (Casagrande and Joseph, 1980). The blind spot representation is another region where binocular competition is absent in striate cortex. Because the left eye's blind spot representation receives input from the right eye only, one would predict no shrinkage after 

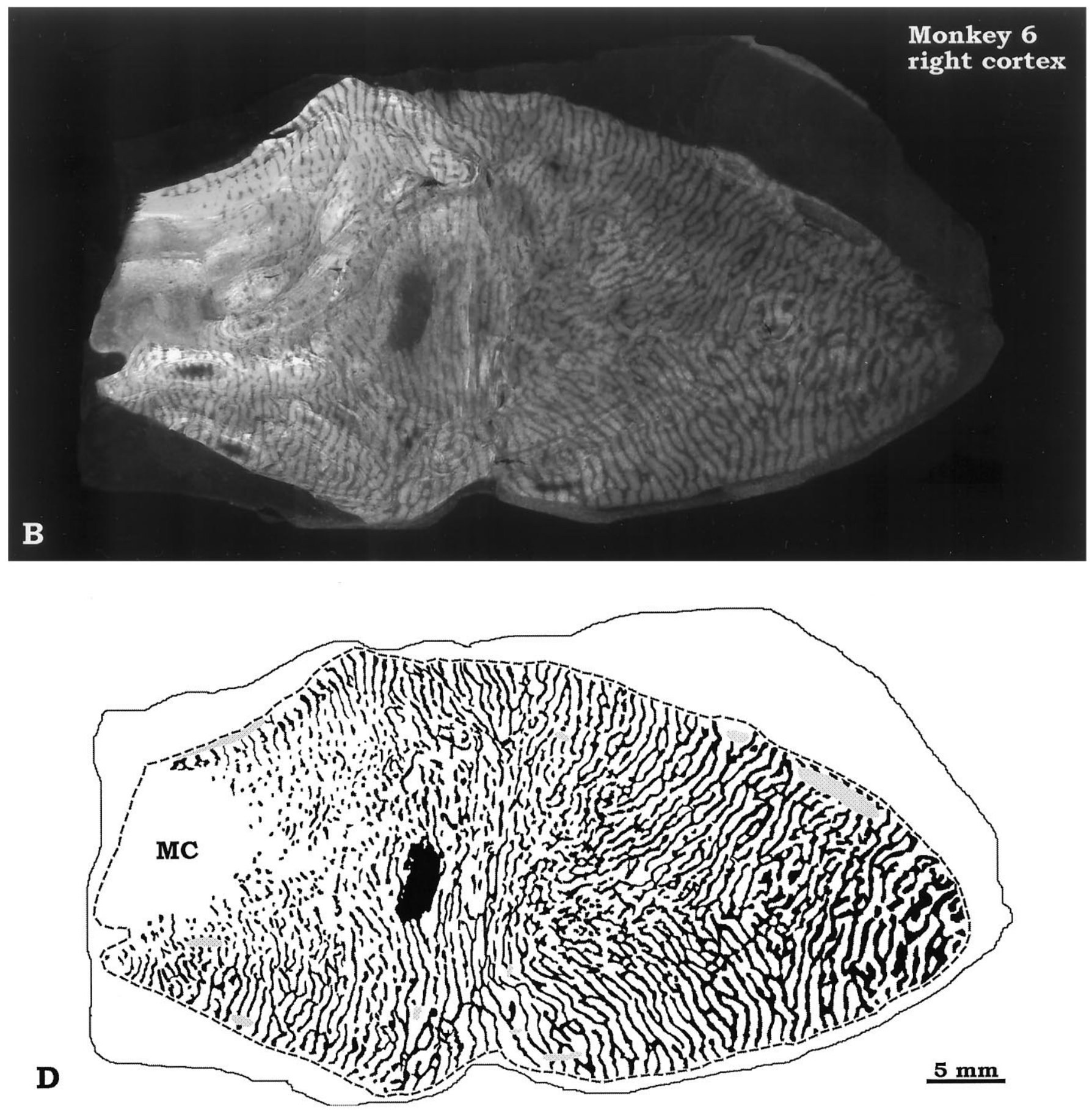

Figure 13 continued.

suture of the right eye. However, we observed clear shrinkage of the blind spot in the right cortex of Monkeys 3 and 4. Closure of the right eye stimulated geniculocortical afferents of the left eye to invade a region where they have no competitive advantage, because they are not driven by visual images falling on the blind spot. We have no clear explanation for this finding. It appears that shrinkage of the blind spot was limited by the maximum capacity of geniculocortical afferents to expand and retract, not by the privileged status of a monocular region. We estimate that the maximum column shrinkage in striate cortex after lid suture at 1 week is just under $500 \mu \mathrm{m}$ (this rough figure is derived from Fig. $9 B$ : most columns in this mosaic were obliterated, except those near the V1/V2 border, which average $>500 \mu \mathrm{m})$. The blind spot averages $5.0 \mathrm{~mm} \times 2.5 \mathrm{~mm}$ in normal macaques, with an area of $10 \mathrm{~mm}^{2}$ (Horton and Hocking, 1996c). Suture at age 1 week would be expected to reduce the dimensions to $\sim 4.0 \mathrm{~mm} \times 1.5 \mathrm{~mm}$, area $\sim 4-5 \mathrm{~mm}^{2}$, close to the size in Figure 9, $B$ and $D$. Therefore, monocular regions like the blind spot and temporal crescent survive because they are too large to be overrun by the open eye, not because they are immune to invasion. 

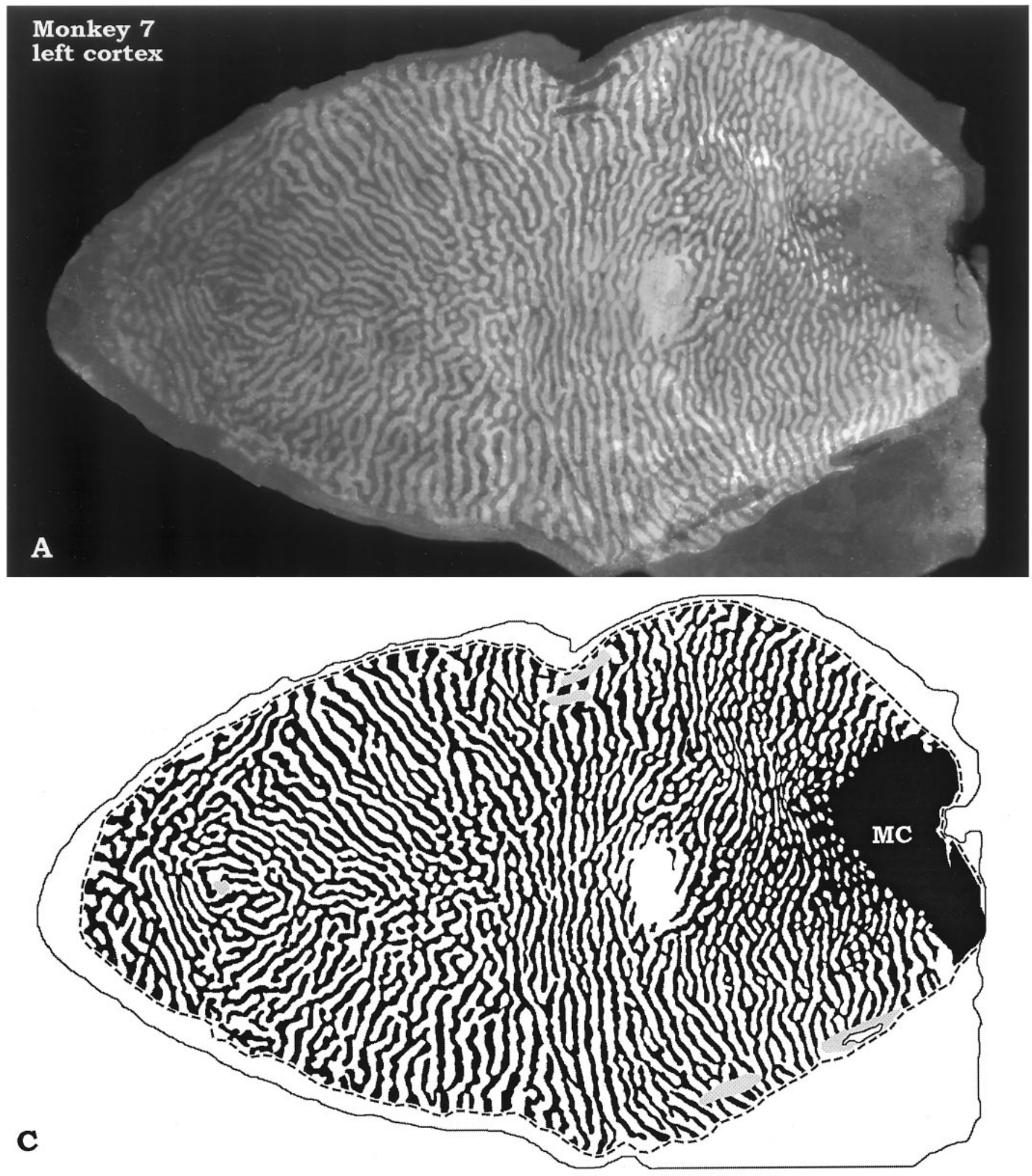

Figure 14. Monkey 7 (7 week suture). Montages of layer IVc $\beta$ showed only mild shrinkage of the unlabeled columns of the right eye, signifying that the cortex was less vulnerable to the effects of visual deprivation by age 7 weeks. Note the gargantuan proportions of V1 and its columns in this animal compared with Monkey 5 (Fig. 12) and Monkey 6 (Fig. 13). Figure continues.

\section{Clinical implications}

Our data offer further rationale for removal of dense, unilateral cataract at the earliest possible age. In macaque striate cortex, we show that damage to the functional architecture from monocular occlusion begins to accrue right from birth. Severe fragmentation (and obliteration in many areas) of columns was seen only in animals sutured at age 1 week. Less than 1 week of form deprivation during the critical period is sufficient to remodel axonal arbors in visual 

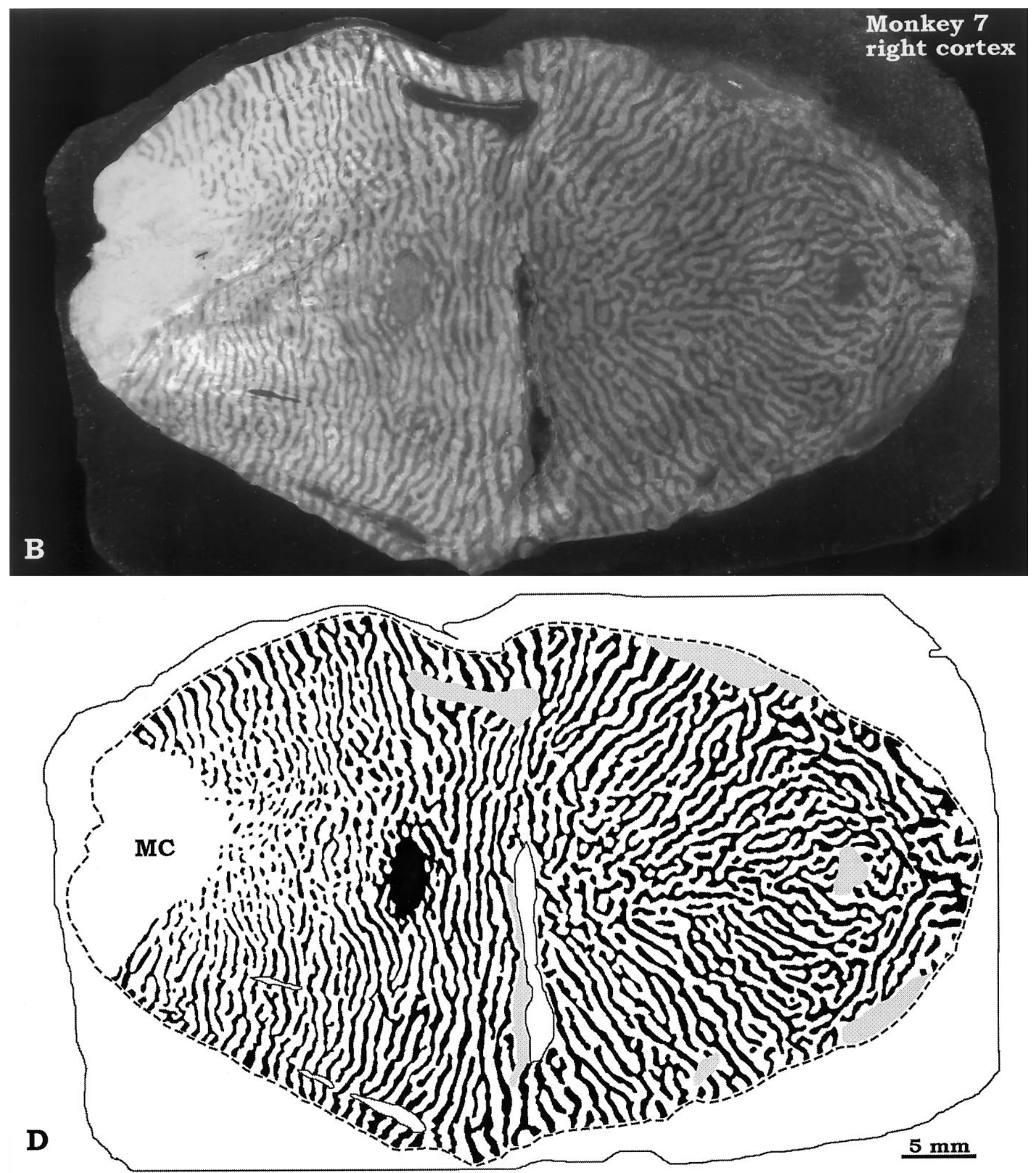

Figure 14 continued.

cortex (Antonini and Stryker, 1993, 1996) and to shift the ocular preference of neurons (Hubel and Wiesel, 1970; Movshon and Dürsteler, 1977). These changes can be reversed at any time during the first few months of life by opening the deprived eye and closing the normal eye (Blakemore and Van Sluyters, 1974; Movshon and Blakemore, 1974; Vital-Durand et al., 1978; Blakemore et al., 1978; Olson and Freeman, 1978; Tigges et al., 1992; Boothe et al., 1996). However, the more prolonged the deprivation, the more aggressively 

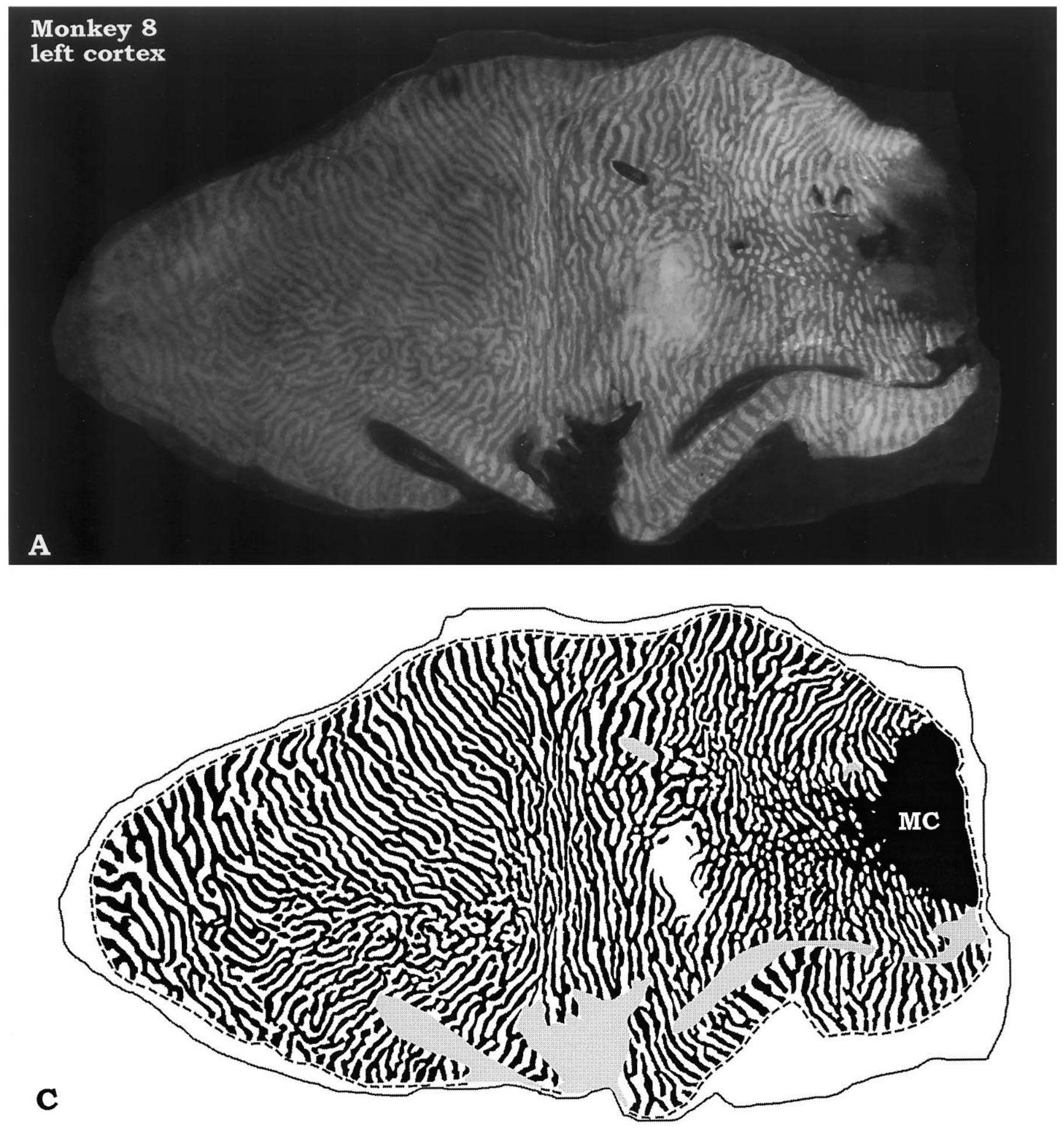

Figure 15. Monkey 8 (12 week suture). Area measurements in layer IVc $\beta$ showed normal column areas, indicating that the critical period for expansion/contraction of columns was over by age 3 months. This animal had prominent widening of its ocular dominance columns within the foveal representation and along the V1/V2 border (dashed line), an effect seen (to a variable extent) in all animals. Figure continues.

the normal eye must be patched to compensate. The price of intensive patching therapy is loss of stereopsis. Gregg and Parks (1992) obtained normal stereopsis of 50 arc-sec in a child with monocular cataract by operating $24 \mathrm{hr}$ after birth. Their experience demon- strates that stereopsis can be preserved by optimal clinical management, and validates the trend toward surgery at the earliest feasible age in infants with dense congenital cataract (Wright et al., 1992; Tytla et al., 1993). 

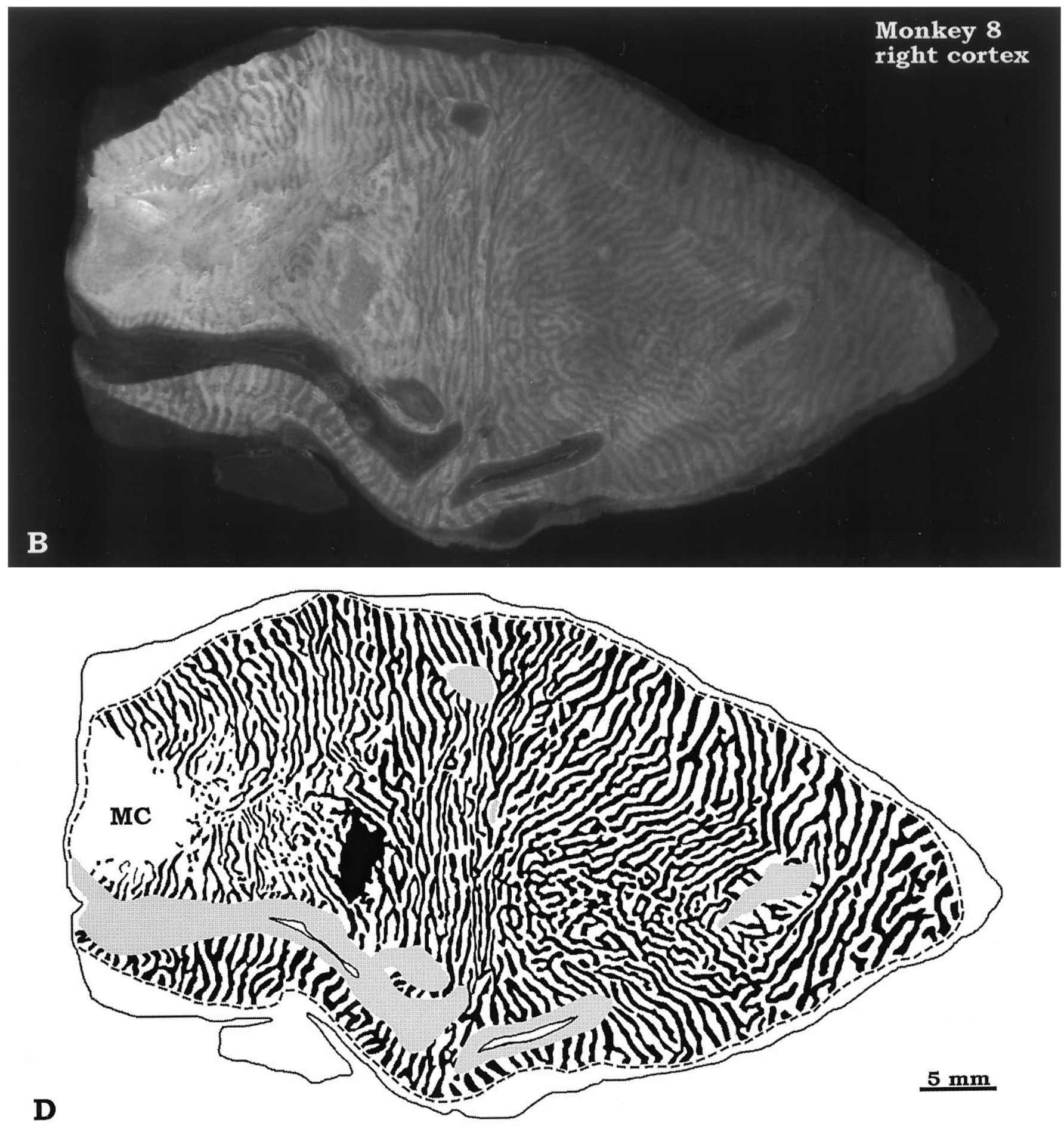

Figure 15 continued.

\section{REFERENCES}

Anderson PA, Olavarria J, Van Sluyters RC (1988) The overall pattern of ocular dominance bands in cat visual cortex. J Neurosci 8:2183-2200 Antonini A, Stryker MP (1993) Rapid remodeling of axonal arbors in the visual cortex. Science 260:1819-1821.

Antonini A, Stryker MP (1996) Plasticity of geniculocortical afferents following brief or prolonged monocular occlusion in the cat. J Comp Neurol 369:64-82.

Beller R, Hoyt CS, Marg E, Odom JV (1981) Good visual function after neonatal surgery for congenital monocular cataracts. Am J Ophthalmol 91:559-565.

Birch EE, Stager DR (1988) Prevalence of good visual acuity following surgery for congenital unilateral cataract. Arch Ophthalmol 106:40-43.

Birch EE, Stager DR (1996) The critical period for surgical treatment of dense congenital unilateral cataract. Invest Ophthalmol Vis Sci 37:1532-1538.

Birch EE, Swanson WH, Stager DR, Woody M, Everett M (1993) Outcome after very early treatment of dense congenital unilateral cataract. Invest Ophthalmol Vis Sci 34:3687-3699. 
Blakemore C, Van Sluyters RC (1974) Reversal of the physiological effects of monocular deprivation in kittens: further evidence for a sensitive period. J Physiol (Lond) 237:195-216.

Blakemore C, Garey LJ, Vital-Durand F (1978) The physiological effects of monocular deprivation and their reversal in the monkey's visual cortex. J Physiol (Lond) 283:223-262.

Boothe RG, Dobson V, Teller DY (1985) Postnatal development of vision in human and nonhuman primates. Annu Rev Neurosci 8:495-545.

Boothe RG, Louden TM, Lambert SR (1996) Acuity and contrast sensitivity in monkeys after neonatal intraocular lens implantation with and without parttime occlusion of the fellow eye. Invest Ophthalmol Vis Sci 37:1520-1531.

Casagrande VA, Joseph R (1980) Morphological effects of monocular deprivation and recovery on the dorsal lateral geniculate nucleus in galago. J Comp Neurol 194:413-426.

Cheng KP, Hiles DA, Biglan AW, Pettapiece MC (1991) Visual results after early surgical treatment of unilateral congenital cataracts. Ophthalmology 98:903-910.

Cordes FC (1957) Failure in congenital cataract surgery. Am J Ophthalmol 43:1-21.

Costenbader FD, Albert DG (1957) Conservatism in the management of congenital cataract. Arch Ophthalmol 58:426-430.

Daw NW, Fox K, Sato H, Czepita D (1992) Critical period for monocular deprivation in the cat visual cortex. J Neurophysiol 67:197-202.

Drummond GT, Scott WE, Keech RV (1989) Management of monocular congenital cataracts. Arch Ophthalmol 107:45-51.

Enoch JM, Rabinowicz IM (1976) Early surgery and visual correction of an infant born with unilateral eye lens opacity. Documenta Ophthalmol 41:371-382.

Fitzpatrick D, Itoh K, Diamond IT (1983) The laminar organization of the lateral geniculate body and the striate cortex in the squirrel monkey (Saimiri sciureus). J Neurosci 3:673-702.

Florence SL, Kaas JH (1992) Ocular dominance columns in area 17 of old world macaque and talapoin monkeys: complete reconstructions and quantitative analyses. Vis Neurosci 8:449-462.

François J (1979) Late results of congenital cataract surgery. Ophthalmology 86:1586-1598.

Gregg FM, Parks MM (1992) Stereopsis after congenital monocular cataract extraction. Am J Ophthalmol 114:314-317.

Guillery RW, Stelzner DJ (1970) The differential effects of unilateral lid closure upon the monocular and binocular segments of the dorsal lateral geniculate nucleus in the cat. J Comp Neurol 139:413-422.

Hata Y, Stryker MP (1994) Control of thalamocortical afferent rearrangement by postsynaptic activity in developing visual cortex. Science 265:1732-1735.

Hendrickson AE, Wilson JR, Ogren MP (1978) The neuroanatomical organization of pathways between the dorsal lateral geniculate nucleus and visual cortex in old world and new world primates. J Comp Neurol 182:123-136.

Hendrickson AE, Movshon JA, Eggers HM, Gizzi MS, Boothe RG, Kiorpes L (1987) Effects of early unilateral blur on the macaque's visual system. II. Anatomical observations. J Neurosci 7:1327-1339.

Hendry SHC, Yoshioka T (1994) A neurochemically distinct third channel in the macaque dorsal lateral geniculate nucleus. Science 264:575-577.

Hess EH (1973) Imprinting: early experience and the developmental psychobiology of attachment. New York: Van Nostrand Reinhold.

Horton JC (1984) Cytochrome oxidase patches: a new cytoarchitectonic feature of monkey visual cortex. Philos Trans R Soc Lond [Biol] 304:199-253.

Horton JC, Hocking DR (1996a) An adult-like pattern of ocular dominance columns in striate cortex of newborn monkeys prior to visual experience. J Neurosci 16:1791-1807.

Horton JC, Hocking DR (1996b) Anatomical demonstration of ocular dominance columns in striate cortex of the squirrel monkey. J Neurosci 16:5510-5522.

Horton JC, Hocking DR (1996c) Intrinsic variability of ocular dominance column periodicity in normal macaque monkeys. J Neurosci 16:7228-7239.

Horton JC, Hubel DH (1981) Regular patchy distribution of cytochrome oxidase staining in primary visual cortex of macaque monkey. Nature 292:762-764.

Horton JC, Stryker MP (1993a) Amblyopia induced by anisometropia without shrinkage of ocular dominance columns in human striate cortex. Proc Natl Acad Sci USA 90:5494-5498.

Horton JC, Stryker MP (1993b) Ocular dominance columns within the foveal representation of macaque striate cortex are less susceptible to shrinkage induced by early monocular deprivation. Soc Neurosci Abstr 19:370.19.

Hubel DH, Wiesel TN (1970) The period of susceptibility to the physiological effects of unilateral eye closure in kittens. J Physiol (Lond) 206:419-436.

Hubel DH, Wiesel TN, LeVay S (1977) Plasticity of ocular dominance columns in monkey striate cortex. Philos Trans R Soc Lond [Biol] 278:377-409.

Itaya SK, Itaya PW, Van Hoesen GW (1984) Intracortical termination of the retino-geniculo-striate pathway studied with transsynaptic tracer (wheat germ agglutinin-horseradish peroxidase) and cytochrome oxidase staining in the macaque monkey. Brain Res 304:303-310.

Kaas JH, Lin CS, Casagrande VA (1976) The relay of ipsilateral and contralateral retinal input from the lateral geniculate nucleus to striate cortex in the owl monkey: a transneuronal transport study. Brain Res 106:371-378.

LeVay S, Stryker MP, Shatz CJ (1978) Ocular dominance columns and their development in layer IV of the cat's visual cortex: a quantitative study. J Comp Neurol 179:223-244.

LeVay S, Wiesel TN, Hubel DH (1980) The development of ocular dominance columns in normal and visually deprived monkeys. J Comp Neurol 191:1-51.

LeVay S, Connolly M, Houde J, Van Essen DC (1985) The complete pattern of ocular dominance stripes in the striate cortex and visual field of the macaque monkey. J Neurosci 5:486-501.

Livingstone MS, Hubel DH (1982) Thalamic inputs to cytochrome oxidase-rich regions in monkey visual cortex. Proc Natl Acad Sci USA 79:6098-6101.

Lorenz KZ (1935) Der Kumpan in der Umwelt des Vogels: die Artgenossen als auslösendes Moment sozialer Verhaltensweisen. J Ornithologie 83:137-213.

Movshon JA, Blakemore C (1974) Functional reinnervation in kitten visual cortex. Nature 251:504-505.

Movshon JA, Dürsteler MR (1977) Effects of brief periods of unilateral eye closure on the kitten's visual system. J Neurophysiol 40:1255-1265.

Movshon JA, Egger HM, Gizzi MS, Hendrickson AE, Kiorpes L, Boothe RG (1987) Effects of early unilateral blur on the macaque's visual system. III. Physiological observations. J Neurosci 7:1340-1351.

Olavarria J, Van Sluyters RC (1985) Unfolding and flattening the cortex of gyrencephalic brains. J Neurosci Methods 15:191-202.

Olson CR, Freeman RD (1978) Monocular deprivation and recovery during sensitive period in kittens. J Neurophysiol 41:65-74.

Olson CR, Freeman RD (1980) Profile of the sensitive period for monocular deprivation in kittens. Exp Brain Res 39:17-21.

Parks MM, Hiles DA (1967) Management of infantile cataracts. Am J Ophthalmol 63:10-19.

Pratt-Johnson JA, Tillson G (1981) Visual results after removal of congenital cataracts before the age of 1 year. Can J Ophthalmol 16:19-27.

Rakic P (1977) Prenatal development of the visual system in rhesus monkey. Philos Trans R Soc Lond [Biol] 278:245-260.

Rogers GL, Tishler CL, Tsou BH, Hertle RW, Fellows RR (1981) Visual acuities in infants with congenital cataracts operated on prior to 6 months of age. Arch Ophthalmol 99:999-1003.

Rosa MGP, Gatass R, Fiorani Jr M (1988) Complete pattern of ocular dominance stripes in V1 of a new world monkey, Cebus apella. Exp Brain Res 72:645-648.

Ryan SJ, Blanton FM, Von Noorden GK (1965) Surgery of congenital cataract. Am J Ophthalmol 60:583-587.

Shatz CJ, Lindström S, Wiesel TN (1977) The distribution of afferents representing the right and left eyes in the cat's visual cortex. Brain Res 131:103-116.

Shatz CJ, Stryker MP (1978) Ocular dominance in layer IV of the cat's visual cortex and the effects of monocular deprivation. J Physiol (Lond) 281:267-283.

Sparks DL, Mays LE, Gurski MR, Hickey TL (1986) Long- and shortterm monocular deprivation in the rhesus monkey: effects on visual fields and optokinetic nystagmus. J Neurosci 6:1771-1780.

Spatz WB (1979) The retino-geniculo-cortical pathway in Callithrix. II. The geniculo-cortical projection. Exp Brain Res 36:401-410.

Swindale NV, Vital-Durand F, Blakemore C (1981) Recovery from mo- 
nocular deprivation in the monkey. III. Reversal of anatomical effects in the visual cortex. Proc R Soc Lond [Biol] 213:435-450.

Tigges M, Boothe RG, Tigges J, Wilson JR (1992) Competition between an aphakic and an occluded eye for territory in striate cortex of developing rhesus monkeys: cytochrome oxidase histochemistry in layer $4 \mathrm{C}$. J Comp Neurol 316:173-186.

Tootell RBH, Silverman MS (1985) Two methods for flat-mounting cortical tissue. J Neurosci Methods 15:177-190.

Tytla ME, Lewis TL, Maurer D, Brent HP (1993) Stereopsis after congenital cataract. Invest Ophthalmol Vis Sci 34:1767-1773.

Vaegan, Taylor D (1979) Critical period for deprivation amblyopia in children. Trans Ophthalmol Soc [UK] 99:432-439.

Van Essen DC, Newsome WT, Maunsell JHR (1984) The visual field representation in striate cortex of the macaque monkey: asymmetries, anisotropies, and individual variability. Vision Res 24:429-448.

Vital-Durand F, Garey LJ, Blakemore C (1978) Monocular and binocular deprivation in the monkey: morphological effects and reversibility. Brain Res 158:45-64.

von Noorden GK, Middleditch PR (1975) Histology of the monkey's lateral geniculate nucleus after unilateral lid closure and experimenta strabismus: further observations. Invest Ophthalmol Vis Sci 14:674-683. von Noorden GK, Crawford MLJ, Middleditch PR (1976) The effects of monocular visual deprivation: disuse or binocular interaction? Brain Res 111:277-285.

Weber JT, Huerta MF, Kaas JH, Harting JK (1983) The projections of the lateral geniculate nucleus of the squirrel monkey: studies of the interlaminar zones and the S layers. J Comp Neurol 213:135-145.

Wiesel TN (1982) Postnatal development of the visual cortex and the influence of environment. Nature 299:583-591.

Wiesel TN, Hubel DH (1963) Single-cell responses in striate cortex of kittens deprived of vision in one eye. J Neurophysiol 26:1003-1017.

Wiesel TN, Hubel DH (1965) Comparison of the effects of unilateral and bilateral eye closure on cortical unit responses in kittens. J Neurophysiol 28:1029-1040.

Wiesel TN, Hubel DH, Lam DMK (1974) Autoradiographic demonstration of ocular-dominance columns in the monkey striate cortex by means of transneuronal transport. Brain Res 79:273-279.

Wong-Riley M (1979) Changes in the visual system of monocularly sutured or enucleated kittens demonstrable with cytochrome oxidase histochemistry. Brain Res 171:11-28.

Wright KW, Matsumoto E, Edelman PM (1992) Binocular fusion and stereopsis associated with early surgery for monocular congenital cataracts. Arch Ophthalmol 110:1607-1609. 